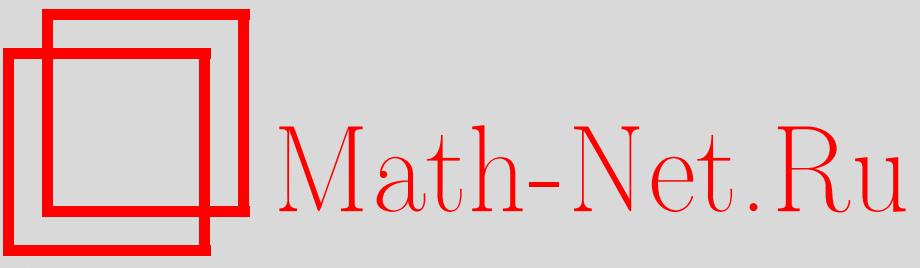

A. G. Chentsov, P. A. Chentsov, The routing problems with optimization of the starting point: dynamic programming, Izv. IMI UdGU, 2019, Volume 54, 102-121

DOI: https://doi.org/10.20537/2226-3594-2019-54-08

Use of the all-Russian mathematical portal Math-Net.Ru implies that you have read and agreed to these terms of use

http://www.mathnet.ru/eng/agreement

Download details:

IP : 54.172 .240 .79

April 26, 2023, 16:02:11 
Izvestiya Instituta Matematiki i Informatiki Udmurtskogo Gosudarstvennogo Universiteta

2019. Volume 54. Pp. 102-121

MSC2010: 93C83

(C) A. G. Chentsov, P. A. Chentsov

\section{THE ROUTING PROBLEMS WITH OPTIMIZATION OF THE STARTING POINT: DYNAMIC PROGRAMMING}

The extreme routing problem focused on engineering applications in mechanical engineering is considered. We mean the well-known task of tool controlling in the CNC sheet cutting machines. A mathematical model is presented which includes a system of megalopolises (nonempty finite sets) and cost functions depending on the list of tasks. Megalopolises are constructed on the basis of discretization of equidistant curves of part contours. The dependence on the list of tasks is connected with reasons associated with the dynamic constraints that arise in the process of task completion. Among all restrictions, the conditions of precedence are distinguished (earlier cutting of the inner contours and more earlier cutting of large parts). Rational consideration of the precedence conditions allows one to reduce the complexity of calculations when widely understood dynamic programming (DP) is used in the implementation that develops R. Bellman's scheme. This approach makes it possible to solve the problem of optimizing complexes, which include the initial state (starting point), the method of numbering megalopolises in the order of their visits, and the specific trajectory of the process. For a problem complicated by the dependence of the terminal function on the initial state, a decomposition algorithm is used, which allows, in a substantial part of the procedure, the application of a single (for all initial states) DP scheme. The optimal algorithm based on DP is implemented as a program for PC; a computational experiment is conducted.

Keywords: routing problem, dynamic programming, precedence conditions.

DOI: $10.20537 / 2226-3594-2019-54-08$

\section{Introduction}

Routing problems arise in many applications. In particular, these problems arise in investigating sheet cutting on CNC machines. Another applied problem related to routing is that of minimization of radiation dose of employees for the work complex under increased radiation; the above-mentioned radiation dose depends on the route selected for work execution. Of course, many other applied problems with elements of routing exist. Therefore, investigation of routing problems is of much current interest.

Of course, the well-known TSP [1,2] can be considered as a prototype of the above-mentioned routing problems. But many new difficulties arise. These difficulties have both numerical and qualitative nature. These difficulties are related to diverse constraints and complicated cost functions; they are generated by requirements of applied problems. We note separately precedence conditions. So, for sheet cutting on CNC machines, these conditions arise by concepts of precutting of interior contours of details. Moreover, under these conditions some technological requirements can be taken into account. So, we can require that large details be cut out earlier than the small ones.

Other constraints can be related to works already done. Such constraints can be called dynamic: roughly speaking, we should avoid thin jumpers and domains with poor heat dissipation. These restrictions can be taken into account through the introduction of penalties. As a result, cost functions admitting the dependence on the list of tasks arise.

In the above-mentioned problem, megalopolises arise under discretization of equidistant curves of contours. So, originally, we have a discrete-continuous extremal problem. In addition, megalopolises are typically large; therefore, we have the extremal problem of perceptible 
dimension. Thus, numerical difficulties inherent in the task TSP are saved and, what is more, aggravated.

Now we note a useful circumstance. It is related to the problem of the starting point optimization. This problem has received fairly little attention. In the present article, we consider all above-mentioned singularities. As a result, we obtain more complicated investigation than one in the TSP task. We are oriented to applied problems related to sheet cutting. But special attention is given to the question of the starting point optimization. This article is a natural continuation of $[3,4]$.

In our investigation, the basic method is dynamic programming (DP). We use a variant of the DP procedure that is a serious development of the Bellman procedure (see [5]): we use the retrograde construction of the Bellman function (in the investigation of TSP, the variant of Held and Karp [6] is used more often). The used variant of the DP procedure is more appropriate for the starting point optimization. We note that this variant was also implemented for the "nonadditive" routing problem in [7]; in addition, optimization of the starting point was realized in this problem also.

It is useful to note that, for some versions of our problems, the requirement about return to the starting point arises. Then, the used variant of DP procedure is complicated. Namely, in this case, our DP procedure depends on the starting point. For this setting, in [4], the decomposition solution was constructed. In this article, we combine constructions of $[3,4]$.

\section{$\S 1$. General notions and designations}

We use standard set-theoretical symbolics (quantors, propositional connectives etc.); we denote the empty set by $\emptyset$ and equality by definition by $\triangleq$. A family is a set of sets. If $x$ and $y$ are objects, then by $\{x ; y\}$ we denote the nonempty set for which $x \in\{x ; y\}, y \in\{x ; y\}$, and $\forall z \in\{x ; y\}$

$$
(x=z) \vee(y=z) .
$$

So, we have an unordered pair of objects $x$ and $y$. Of course, for every object $h$, the set $\{h\} \triangleq\{h ; h\}$ is the singleton containing $h$. In accordance with [8, ch. II, §3], for every objects $\alpha$ and $\beta$, the ordered pair (OP) $(\alpha, \beta)$ with the first element $\alpha$ and the second element $\beta$ is defined as $(\alpha, \beta) \triangleq\{\{\alpha\} ;\{\alpha ; \beta\}\}$. If $z$ is an arbitrary OP, then by $\operatorname{pr}_{1}(z)$ and $\operatorname{pr}_{2}(z)$ we denote the first and the second element of $z$, respectively. For every three objects $a, b$, and $c$, in the form of $(a, b, c) \triangleq((a, b), c)$, the (ordered) triplet with the first element $a$, the second element $b$, and the third element $c$ is defined. In this connection, we recall that, for every three sets $A, B$, and $C$, the set $A \times B \times C$ is defined as $A \times B \times C \triangleq(A \times B) \times C$; see [9, ch. 1, §3]. These stipulations will be essential in what follows. If $P$ and $Q$ are nonempty sets, then by $Q^{P}$ we denote (see [8, ch. II, $\S 6]$ ) the set of all mappings from $P$ into $Q$; of course, these mappings are functions from $P$ into $Q$ (as usual, under $f \in Q^{P}$ and $x \in P$, in the form of $f(x) \in Q$, the value of mapping $f$ at the point $x$ is realized).

For every set $H$, by $\mathcal{P}(H)$ and $\mathcal{P}^{\prime}(H)$ we denote a family of all subsets and all nonempty subsets of $H$, respectively; we suppose that $\operatorname{Fin}(H)$ is a family of all finite subsets of $H$. So, Fin $(H)$ is a family of all nonempty finite subsets of $H$; if $H$ is a nonempty finite set, then $\operatorname{Fin}(H)=\mathcal{P}^{\prime}(H)$.

If $P$ and $Q$ are nonempty sets, $h \in Q^{P}$, and $A \in \mathcal{P}(P)$, then $h^{1}(A) \triangleq\{h(x): x \in A\}$ is the image of $A$ under operation $f$.

In the following, $\mathbb{R}$ is a real line, $\mathbb{R}_{+} \triangleq\{\xi \in \mathbb{R} \mid 0 \leqslant \xi\}, \mathbb{N} \triangleq\{1 ; 2 ; \ldots\} \in \mathcal{P}^{\prime}\left(\mathbb{R}_{+}\right)$, $\mathbb{N}_{0} \triangleq\{0\} \bigcup \mathbb{N}=\{0 ; 1 ; 2 ; \ldots\} \in \mathcal{P}^{\prime}\left(\mathbb{R}_{+}\right)$, and

$$
\overline{p, q} \triangleq\left\{k \in \mathbb{N}_{0} \mid(p \leqslant k) \&(k \leqslant q)\right\} \in \mathcal{P}\left(\mathbb{N}_{0}\right) \quad \forall p \in \mathbb{N}_{0} \forall q \in \mathbb{N}_{0}
$$


(we note that $\overline{1, m}=\{k \in \mathbb{N} \mid k \leqslant m\}$ under $m \in \mathbb{N}$; moreover, $\overline{1,0}=\emptyset$ ). For every nonempty finite set $K$, the number $|K| \in \mathbb{N}$ is cardinality of the set $K$; by (bi) $[K]$ we denote the set of all bijections $[10, \S 5.3]$ from $\overline{1,|K|}$ onto $K$. As usual, $|\emptyset| \triangleq 0$.

For every nonempty set $S$, by $\mathcal{R}_{+}[S]$ we denote the set of all nonnegative (real-valued) functions from $S$ into $\mathbb{R}$; so, $\mathcal{R}_{+}[S] \triangleq\left(\mathbb{R}_{+}\right)^{S}$.

\section{§2. Setting the problem}

In the following, we fix a nonempty set $X$ and $X^{0} \in \mathcal{P}^{\prime}(X)$. So, $X^{0}$ is a nonempty subset of $\mathrm{X}$. Elements of $X^{0}$ are used as starting points of the processes under study. Fix $N \in \mathbb{N}$ for which $N \geqslant 2$, and

$$
M_{1} \in \operatorname{Fin}(X), \quad \ldots, \quad M_{N} \in \operatorname{Fin}(X) .
$$

We consider the sets (2.1) as megalopolises and suppose that

$$
\left(X^{0} \bigcap M_{j}=\emptyset \forall j \in \overline{1, N}\right) \&\left(M_{p} \bigcap M_{q}=\emptyset \quad \forall p \in \overline{1, N} \quad \forall q \in \overline{1, N} \backslash\{p\}\right) .
$$

Conditions (2.2) are typical for routing problems. We fix (nonempty) relations

$$
\mathbb{M}_{1} \in \mathcal{P}^{\prime}\left(M_{1} \times M_{1}\right), \quad \ldots, \quad \mathbb{M}_{N} \in \mathcal{P}^{\prime}\left(M_{N} \times M_{N}\right) .
$$

Under $j \in \overline{1, N}$, the relation $\mathbb{M}_{j}$ defines all possible variants for interior permutations: if $z \in \mathbb{M}_{j}$, then $\operatorname{pr}_{1}(z) \in M_{j}$ is the arrival point and $\operatorname{pr}_{2}(z) \in M_{j}$ is the point of departure from $M_{j}$. Permutation from $\operatorname{pr}_{1}(z)$ to $\operatorname{pr}_{2}(z)$ means that some works called internal are performed. Let $\mathbb{P} \triangleq($ bi $)[\overline{1, N}]$ (the set of all routes in the complete problem). We match a bundle of trajectories to each route. So, we consider processes of the type

$$
\left(x \in X^{0}\right) \rightarrow\left(x_{1}^{(1)} \in M_{\alpha(1)} \rightsquigarrow x_{2}^{(1)} \in M_{\alpha(1)}\right) \rightarrow \ldots \rightarrow\left(x_{1}^{(N)} \in M_{\alpha(N)} \rightsquigarrow x_{2}^{(N)} \in M_{\alpha(N)}\right)
$$

for which $z_{1} \triangleq\left(x_{1}^{(1)}, x_{2}^{(1)}\right) \in \mathbb{M}_{\alpha(1)}, \ldots, z_{N} \triangleq\left(x_{1}^{(N)}, x_{2}^{(N)}\right) \in \mathbb{M}_{\alpha(N)}$. So, relations (2.3) define constraints for internal permutations. By (2.4) the trajectory bundle corresponding to route $\alpha$ is defined at a meaningful level. Later, this bundle will be determined strictly.

Now we introduce precedence conditions for which the relation $\mathbf{K} \in \mathcal{P}(\overline{1, N} \times \overline{1, N})$ is fixed (the case $\mathbf{K}=\emptyset$ is not excluded; in this case, constraints in the form of precedence conditions are lacking). We suppose that $\forall \mathbf{K}_{0} \in \mathcal{P}^{\prime}(\mathbf{K}) \exists z_{0} \in \mathbf{K}_{0}: \operatorname{pr}_{1}\left(z_{0}\right) \neq \operatorname{pr}_{2}(z) \forall z \in \mathbf{K}_{0}$. Then $[11,(2.2 .53)]$

$$
\begin{gathered}
\mathbf{A} \triangleq\{\alpha \\
\quad \in \mathbb{P} \mid\left(\forall t_{1} \in \overline{1, N} \forall t_{2} \in \overline{1, N}\left(\left(\alpha\left(t_{1}\right), \alpha\left(t_{2}\right)\right) \in \mathbf{K}\right) \Rightarrow\left(t_{1}<t_{2}\right)\right\}= \\
=\left\{\alpha \in \mathbf{P} \mid \alpha^{-1}\left(\operatorname{pr}_{1}(z)\right)<\alpha^{-1}\left(\operatorname{pr}_{2}(z)\right) \forall z \in \mathbf{K}\right\} \in \mathcal{P}^{\prime}(\mathbb{P})
\end{gathered}
$$

is a set of all $\mathbf{K}$-admissible (admissible by precedence) routes. Of course, $\mathbf{A} \in \operatorname{Fin}(\mathbb{P})$; see (2.5).

Now we suppose that for every $j \in \overline{1, N}$

$$
\left(\mathfrak{M}_{j} \triangleq\left\{\operatorname{pr}_{1}(z): z \in \mathbb{M}_{j}\right\}\right) \&\left(\mathbf{M}_{j} \triangleq\left\{\operatorname{pr}_{2}(z): z \in \mathbb{M}_{j}\right\}\right) ;
$$

every of sets (2.6) is nonempty. In (2.6), we have subsets of $M_{j}$. Then

$$
\left(\tilde{\mathbb{X}} \triangleq\left(\bigcup_{i=1}^{N} \mathfrak{M}_{i}\right) \bigcup X^{0} \in \mathcal{P}^{\prime}(X)\right) \&\left(\mathbf{X} \triangleq\left(\bigcup_{i=1}^{N} \mathbf{M}_{i}\right) \bigcup X^{0} \in \mathcal{P}^{\prime}(X)\right) .
$$

Moreover, $\mathbb{X} \triangleq \tilde{\mathbb{X}} \cup \mathbf{X} \in \mathcal{P}^{\prime}(X)$. By $\mathbb{Z}$ we denote the set of all collections

$$
\left(z_{t}\right)_{t \in \overline{0, N}}: \overline{0, N} \longrightarrow \tilde{\mathbb{X}} \times \mathbf{X}
$$


of course, under each collection (2.8) and $\tau \in \overline{0, N}$, the inclusion $z_{\tau} \in \mathbb{X} \times \mathbb{X}$ is realized. In addition,

$$
\begin{gathered}
\mathcal{Z}_{\alpha}[x] \triangleq\left\{\left(z_{t}\right)_{t \in \overline{0, N}} \in \mathbb{Z} \mid\left(z_{0}=(x, x)\right) \&\right. \\
\left.\&\left(z_{t} \in \mathbb{M}_{\alpha(t)} \forall t \in \overline{1, N}\right)\right\} \in \operatorname{Fin}(\mathbb{Z}) \quad \forall \alpha \in \mathbb{P} \quad \forall x \in X^{0} .
\end{gathered}
$$

In (2.9), we use (2.1) and (2.3): under $j \in \overline{1, N}$, the inclusion $\mathbb{M}_{j} \in \operatorname{Fin}(\tilde{\mathbb{X}} \times \mathbf{X})$ is realized. Using (2.5) and (2.9), we find that under $x \in X^{0}$

$$
\tilde{\mathbf{D}}[x] \triangleq\left\{\left(\alpha,\left(z_{t}\right)_{i \in \overline{0, N}}\right) \in \mathbf{A} \times \mathbb{Z} \mid\left(z_{t}\right)_{t \in \overline{0, N}} \in \mathcal{Z}_{\alpha}[x]\right\} \in \operatorname{Fin}(\mathbf{A} \times \mathbb{Z})
$$

is the set of all admissible solutions corresponding to the starting point $x$. As a corollary,

$$
\mathbf{D} \triangleq\left\{\left(\alpha,\left(z_{t}\right)_{t \in \overline{0, N}}, x\right) \in \mathbf{A} \times \mathbb{Z} \times X^{0} \mid\left(\alpha,\left(z_{t}\right)_{t \in \overline{0, N}}\right) \in \tilde{\mathbf{D}}[x]\right\}
$$

is the set of all admissible solutions of our complete problem. For exact statement of this problem, we introduce and fix cost functions

$$
\mathbf{c} \in \mathcal{R}_{+}[\mathbf{X} \times \tilde{\mathbb{X}} \times \mathfrak{N}], c_{1} \in \mathcal{R}_{+}[\tilde{\mathbb{X}} \times \mathbf{X} \times \mathfrak{N}], \ldots, c_{N} \in \mathcal{R}_{+}[\tilde{\mathbb{X}} \times \mathbf{X} \times \mathfrak{N}], f \in \mathcal{R}_{+}[\mathbf{X}]
$$

where $\mathfrak{N} \triangleq \mathcal{P}^{\prime}(\overline{1, N})$. In addition, $\mathbf{c}$ is used for estimation of external permutations. The functions $c_{1}, \ldots, c_{N}$ are used for estimation of internal works and $f$ realizes estimation of the terminal state (the point $x_{2}^{(N)}$ in (2.4)). Suppose that under $\alpha \in \mathbb{P}$ and $\left(z_{t}\right)_{t \in \overline{0, N}} \in \mathbb{Z}$

$$
\mathfrak{C}_{\alpha}\left[\left(z_{t}\right)_{t \in \overline{0, N}}\right] \triangleq \sum_{t=1}^{N}\left[\mathbf{c}\left(\operatorname{pr}_{2}\left(z_{t-1}\right), \operatorname{pr}_{1}\left(z_{t}\right), \alpha^{1}(\overline{t, N})\right)+c_{\alpha(t)}\left(z_{t}, \alpha^{1}(\overline{t, N})\right)\right]+f\left(\operatorname{pr}_{2}\left(z_{N}\right)\right) ;
$$

of course, $\mathfrak{C}_{\alpha}\left[\left(z_{t}\right)_{t \in \overline{0, N}}\right] \in \mathbb{R}_{+}$. We use the case $\alpha \in \mathbf{A}$ and $\left(z_{t}\right)_{t \in \overline{0, N}} \in \mathcal{Z}_{\alpha}[x]$, where $x \in X^{0}$; then $\left(\alpha,\left(z_{t}\right)_{t \in \overline{0, N}}\right) \in \tilde{\mathbf{D}}[x]$ (see (2.10)). Under $x \in X^{0}$, we obtain the problem

$$
\mathfrak{C}_{\alpha}\left[\left(z_{t}\right)_{t \in \overline{0, N}}\right] \longrightarrow \min , \quad\left(\alpha,\left(z_{t}\right)_{t \in \overline{0, N}}\right) \in \tilde{\mathbf{D}}[x]
$$

for which the value (extremum) $V[x] \in \mathbb{R}_{+}$is defined as the least of numbers $\mathfrak{C}_{\alpha}\left[\left(z_{t}\right)_{t \in \overline{0, N}}\right]$, $\left(\alpha,\left(z_{t}\right)_{t \in \overline{0, N}}\right) \in \tilde{\mathbf{D}}[x]$, and

$$
(\mathrm{sol})[x] \triangleq\left\{\left(\alpha^{0},\left(z_{t}^{0}\right)_{t \in \overline{0, N}}\right) \in \tilde{\mathbf{D}}[x] \mid \mathfrak{C}_{\alpha^{0}}\left[\left(z_{t}^{0}\right)_{t \in \overline{0, N}}\right]=V[x]\right\} \in \mathcal{P}^{\prime}(\tilde{\mathbf{D}}[x]) .
$$

Of course, (2.14) can be considered (see (2.10)) as a very complicated problem of discrete optimization. This problem was investigated in [12-14]. But now we consider the complete problem

$$
\mathfrak{C}_{\alpha}\left[\left(z_{t}\right)_{t \in \overline{0, N}}\right] \longrightarrow \inf , \quad\left(\alpha,\left(z_{t}\right)_{t \in \overline{0, N}}, x\right) \in \mathbf{D}
$$

as basic; for problem (2.16), the value

$$
\mathbb{V} \triangleq \inf _{\left(\alpha,\left(z_{t}\right)_{t \in \overline{0, N}}, x\right) \in \mathbf{D}} \mathfrak{C}_{\alpha}\left[\left(z_{t}\right)_{t \in \overline{0, N}}\right]=\inf _{x \in X^{0}} V[x] \in \mathbb{R}_{+}
$$

is defined (in (2.17), we have the global extremum) and

$$
\mathbf{S O L} \triangleq\left\{\left(\alpha^{0},\left(z_{t}^{0}\right)_{t \in \overline{0, N}}, x^{0}\right) \in \mathbf{D} \mid \mathfrak{C}_{\alpha^{0}}\left[\left(z_{t}^{0}\right)_{t \in \overline{0, N}}\right]=\mathbb{V}\right\} \in \mathcal{P}(\mathbf{D}) .
$$

We note that the case SOL $=\emptyset$ is possible since the set $X^{0}$ can be infinite; in this case, we strive to find an admissible solution realizing $\mathbb{V}$ with a high degree of accuracy. 


\section{§3. Dynamic programming, 1}

In this section, we consider construction of the Bellman function and its layers. In this connection, we recall the natural construction of extension for problem (2.14); we follow [12-14]. But first we recall the deletion operator of [11, part 2]: suppose that $\mathbf{I} \in \mathfrak{N}^{\mathfrak{N}}$ is defined by the rule

$$
\mathbf{I}(K) \triangleq K \backslash\left\{\operatorname{pr}_{2}(z): z \in \Xi[K]\right\},
$$

where $K \in \mathfrak{N}$ and $\Xi[K] \triangleq\left\{z \in \mathbf{K} \mid\left(\operatorname{pr}_{1}(z) \in K\right) \&\left(\operatorname{pr}_{2}(z) \in K\right)\right\}$. Now we suppose that for $K \in \mathfrak{N}$

$$
(\mathbf{I}-\mathrm{bi})[K] \triangleq\left\{\alpha \in(\mathrm{bi})[K] \mid \alpha(m) \in \mathbf{I}\left(\alpha^{1}(\overline{m,|K|})\right) \quad \forall m \in \overline{1,|K|}\right\} ;
$$

in (3.2), we obtain the set of all admissible (by deletion) local routes; see [13, (3.16)]. In addition, by $[13,(3.17)]$

$$
\mathbf{A}=(\mathbf{I}-\mathrm{bi})[\overline{1, N}] .
$$

Under $K \in \mathfrak{N}$, by $\mathbb{Z}_{K}$ we denote the set of all collections

$$
\left(z_{i}\right)_{i \in \overline{0,|K|}}: \overline{0,|K|} \longrightarrow \mathbb{X} \times \mathbf{X}
$$

For $x \in \mathbf{X}, K \in \mathfrak{N}$, and $\alpha \in(\mathrm{bi})[K]$, we introduce the set

$$
Z[x ; K ; \alpha] \triangleq\left\{\left(z_{i}\right)_{i \in \overline{0,|K|}} \in \mathbb{Z}_{K} \mid\left(z_{0}=(x, x)\right) \&\left(z_{t} \in \mathbb{M}_{\alpha(t)} \forall t \in \overline{1,|K|}\right)\right\} .
$$

We note that (3.4) coincides with $\mathcal{Z}(x, K, \alpha)$ of [14, (3.11)] (of course, in [14, (3.11)], the "point" variant of $X^{0}$ was considiered). If $K \in \mathfrak{N}, \alpha \in(\mathrm{bi})[K]$, and $\left(z_{t}\right)_{t \in \overline{0,|K|}} \in \mathbb{Z}_{K}$, then

$$
\begin{gathered}
\hat{\mathfrak{C}}_{\alpha}\left[\left(z_{t}\right)_{t \in \overline{0,|K|}} \mid K\right] \triangleq \sum_{t=1}^{|K|}\left[\mathbf{c}\left(\operatorname{pr}_{2}\left(z_{t-1}\right), \operatorname{pr}_{1}\left(z_{t}\right), \alpha^{1}(\overline{t,|K|})\right)+\right. \\
\left.+c_{\alpha(t)}\left(z_{t}, \alpha^{1}(\overline{t,|K|})\right)\right]+f\left(\operatorname{pr}_{2}\left(z_{|K|}\right)\right) .
\end{gathered}
$$

We recall that $(\mathbf{I}-\mathrm{bi})[K] \in \mathcal{P}^{\prime}((\mathrm{bi})[K]) \forall K \in \mathfrak{N}$ (see [11, part 2]). Moreover, by (2.3) and (3.4)

$$
Z[x ; K ; \alpha] \in \operatorname{Fin}\left(\mathbb{Z}_{K}\right) \quad \forall x \in \mathbf{X} \quad \forall K \in \mathfrak{N} \quad \forall \alpha \in(\mathrm{bi})[K] .
$$

As a result, for $x \in \mathbf{X}$ and $K \in \mathfrak{N}$, we obtain

$$
\begin{aligned}
\tilde{D}_{K}[x] \triangleq\left\{\left(\alpha,\left(z_{t}\right)_{t \in \overline{0,|K|}}\right)\right. & \left.\in(\mathbf{I}-\mathrm{bi})[K] \times \mathbb{Z}_{K} \mid\left(z_{t}\right)_{t \in \overline{0,|K|}} \in Z[x ; K ; \alpha]\right\} \in \\
& \operatorname{Fin}\left((\mathbf{I}-\mathrm{bi})[K] \times \mathbb{Z}_{K}\right) .
\end{aligned}
$$

Therefore, for $x \in \mathbf{X}$ and $K \in \mathfrak{N}$, the value

$$
v(x, K) \triangleq \min _{\left(\alpha,\left(z_{t}\right)_{t \in \overline{0,|K|})} \in \tilde{D}_{K}[x]\right.} \hat{\mathfrak{C}}_{\alpha}\left[\left(z_{t}\right)_{t \in \overline{0,|K|}} \mid K\right] \in \mathbb{R}_{+}
$$

is defined. Moreover, we suppose that

$$
v(x, \emptyset) \triangleq f(x) \quad \forall x \in \mathbf{X}
$$

By (3.6) and (3.7) we find that values $v(x, K)$ are defined for all positions $(x, K), x \in \mathbf{X}$, $K \in \mathcal{P}(\overline{1, N})$. So, we have the Bellman function $v \in \mathcal{R}_{+}[\mathbf{X} \times \mathcal{P}(\overline{1, N})]$. Now we supplement (3.3). Namely, since $|\overline{1, N}|=N$, we have the inclusion $\mathbb{Z} \subset \mathbb{Z}_{\overline{1, N}}$. In addition, from (3.4), we find that under $x \in X^{0}$, the inclusion $Z[x ; \overline{1, N} ; \alpha] \subset \mathbb{Z}$ holds, where $\alpha \in \mathbb{P}$ (we recall that 
$\mathbb{P}=(\mathrm{bi})[\overline{1, N}])$. And what is more, from (2.9) and (3.4), the equality $\mathcal{Z}_{\alpha}[x]=Z[x ; \overline{1, N} ; \alpha]$ holds, where $x \in X^{0}$ and $\alpha \in \mathbb{P}$. As a corollary, from (2.10) and (3.3), we obtain

$$
\tilde{\mathbf{D}}[x]=\tilde{D}_{\overline{1, N}}[x] \quad \forall x \in X^{0} .
$$

Therefore, under $x \in X^{0}$, the equality

$$
V[x]=v(x, \overline{1, N})
$$

is realized (we use the obvious property (see (2.13) and (3.5)): $\mathfrak{C}_{\alpha}\left[\left(z_{t}\right)_{t \in \overline{0, N}}\right]=\hat{\mathfrak{C}}_{\alpha}\left[\left(z_{t}\right)_{t \in \overline{0, N}} \mid \overline{1, N}\right]$ under $\alpha \in \mathbb{P}$ and $\left.\left(z_{t}\right)_{t \in \overline{0, N}} \in \mathbb{Z}\right)$. From $[14,(4.5)]$, we obtain that

$$
v(x, K)=\min _{j \in \mathbf{I}(K)} \min _{z \in \mathbb{M}_{j}}\left[\mathbf{c}\left(x, \operatorname{pr}_{1}(z), K\right)+c_{j}(z, K)+v\left(\operatorname{pr}_{2}(z), K \backslash\{j\}\right)\right] \forall(x, K) \in \mathbf{X} \times \mathfrak{N} .
$$

$\mathrm{R} \mathrm{e} \mathrm{mark} \mathrm{3.1.} \mathrm{In} \mathrm{connection} \mathrm{with} \mathrm{representation} \mathrm{of} \mathrm{(3.6)} \mathrm{in} \mathrm{the} \mathrm{form} \mathrm{(3.10),} \mathrm{we} \mathrm{note} \mathrm{that} \mathrm{(3.5)}$ corresponds to $[14,(4.1)]$. Therefore, (3.6) is coordinated with [14, (4.3)]. Of course, [14, (4.4)] is the value replaced by function $V[\cdot]$ defined on $X^{0}$. This means that [14, (4.4)] can be used at different starting points (i.e., under different initial states). We can consider our problem as a totality of $x$-problems (2.14) where $x \in X^{0}$ is fixed. Respectively, our Bellman function can be considered as result of combination of all Bellman functions for $x$-problems (2.14).

So, our Bellman function $v$ is defined by (3.10). From (3.9) and (3.10),

$$
V[x]=\min _{j \in \mathbf{I}(\overline{1, N})} \min _{z \in \mathbb{M}_{j}}\left[\mathbf{c}\left(x, \operatorname{pr}_{1}(z), \overline{1, N}\right)+c_{j}(z, \overline{1, N})+v\left(\operatorname{pr}_{2}(z), \overline{1, N} \backslash\{j\}\right)\right] \forall x \in X^{0} .
$$

\section{§4. Dynamic programming, 2: the layers of Bellman function}

In the present section, we use procedure of [14, Section 4] ascending to [11, §4.9]. At least, we recall about essential lists of tasks: we suppose that

$$
\mathfrak{G} \triangleq\left\{K \in \mathfrak{N} \mid \forall z \in \mathbf{K} \quad\left(\operatorname{pr}_{1}(z) \in K\right) \Rightarrow\left(\operatorname{pr}_{2}(z) \in K\right)\right\}
$$

and $\mathfrak{G}_{s} \triangleq\{K \in \mathfrak{G}|s=| K \mid\} \forall s \in \overline{1, N}$. Of course, $\left\{\mathfrak{G}_{1} ; \ldots ; \mathfrak{G}_{N}\right\}$ is a decomposition of $\mathfrak{G}$. In addition, $\mathfrak{G}_{N}=\{\overline{1, N}\}$ and

$$
\mathfrak{G}_{1}=\left\{\{t\}: t \in \overline{1, N} \backslash \mathbf{K}_{1}\right\}
$$

where $\mathbf{K}_{1} \triangleq\left\{\operatorname{pr}_{1}(z): z \in \mathbf{K}\right\}$. In addition [14, (4.6))],

$$
\mathfrak{G}_{s-1}=\left\{K \backslash\{t\}: K \in \mathfrak{G}_{s}, t \in \mathbf{I}(K)\right\} \forall s \in \overline{2, N} .
$$

Along with (4.2) and (4.3), we obtain the next recurrent procedure

$$
\mathfrak{G}_{N} \longrightarrow \mathfrak{G}_{N-1} \longrightarrow \ldots \longrightarrow \mathfrak{G}_{1}
$$

defined by (4.3) and representation of $\mathfrak{G}_{N}$. After realization of $\mathfrak{G}_{1}, \ldots, \mathfrak{G}_{N}$ by (4.4) we construct layers of the position space. For extreme layers $D_{0}$ and $D_{N}$, we suppose that $D_{0} \triangleq\{(x, \emptyset): x \in$ $\tilde{\mathcal{M}}\}$, where

$$
\tilde{\mathcal{M}} \triangleq \bigcup_{j \in \overline{1, N} \backslash \mathbf{K}_{1}} \mathbf{M}_{j},
$$

and $D_{N} \triangleq\left\{(x, \overline{1, N}): x \in X^{0}\right\}$. Of course, $D_{0} \subset \mathbf{X} \times \mathcal{P}(\overline{1, N})$ and $D_{N} \subset \mathbf{X} \times \mathcal{P}(\overline{1, N})$. For intermediate layers $D_{1}, \ldots, D_{N-1}$, we use the procedure of [14, Section 4]. Namely, at first, for $s \in \overline{1, N-1}$ and $K \in \mathfrak{G}_{s}$, we suppose that

$$
\begin{gathered}
J_{s}(K) \triangleq\left\{j \in \overline{1, N} \backslash K \mid\{j\} \bigcup K \in \mathfrak{G}_{s+1}\right\}, \\
\mathcal{M}_{s}[K] \triangleq \bigcup_{j \in J_{s}(K)} \mathbf{M}_{j}, \quad \mathbb{D}_{s}[K] \triangleq\left\{(x, K): x \in \mathcal{M}_{s}[K]\right\} .
\end{gathered}
$$


Using (4.5), we construct the intermediate layers: for $s \in \overline{1, N-1}$, suppose that

$$
D_{s} \triangleq \bigcup_{K \in \mathfrak{G}_{s}} \mathbb{D}_{s}[K]
$$

As a result (see (4.5) and (4.6)), we obtain the layers-sets

$$
D_{s} \in \mathcal{P}^{\prime}(\mathbf{X} \times \mathcal{P}(\overline{1, N})) \forall s \in \overline{0, N}
$$

in this connection, see [11, Proposition 4.9.3]. As a corollary, the constrictions of the Bellman function $v$ are defined: if $t \in \overline{0, N}$, then $v_{t} \in \mathcal{R}_{+}\left[D_{t}\right]$ is realized by the rule

$$
v_{t}(x, K) \triangleq v(x, K) \forall(x, K) \in D_{t} .
$$

In particular, $v_{0} \in \mathcal{R}_{+}\left[D_{0}\right]$ is defined as $v_{0}(x, \emptyset)=v(x, \emptyset)=f(x)$ under $x \in \tilde{\mathcal{M}}$; see (3.7). So, $v_{0}$ is defined by the terminal function $f$. Moreover, $v_{N} \in \mathcal{R}_{+}\left[D_{N}\right]$ is defined by the rule

$$
v_{N}(x, \overline{1, N})=V[x] \forall x \in X^{0} .
$$

So, $v_{N}$ defines the function $V[\cdot]$ and, as a corollary, the global extremum: by (2.17) and (4.9)

$$
\mathbb{V}=\inf _{x \in X^{0}} v_{N}(x, \overline{1, N}) .
$$

We note the known [14, Section 4] property of layers of the position space: for $s \in \overline{1, N}$, $(x, K) \in D_{s}, j \in \mathbf{I}(K)$, and $z \in \mathbb{M}_{j}$, we have

$$
\left(\operatorname{pr}_{2}(z), K \backslash\{j\}\right) \in D_{s-1}
$$

therefore, the value $v_{s-1}\left(\operatorname{pr}_{2}(z), K \backslash\{j\}\right) \in \mathbb{R}_{+}$is defined. From (3.10), (4.8), and (4.11), we obtain that for $s \in \overline{1, N}$, the transformation of $v_{s-1}$ to $v_{s}$ corresponds to the following rule:

$$
v_{s}(x, K)=\min _{j \in \mathbf{I}(K)} \min _{z \in \mathbb{M}_{j}}\left[\mathbf{c}\left(x, \operatorname{pr}_{1}(z), K\right)+c_{j}(z, K)+v_{s-1}\left(\operatorname{pr}_{2}(z), K \backslash\{j\}\right)\right] \quad \forall(x, K) \in D_{s} .
$$

So, we obtain the natural recurrent procedure:

$$
v_{0} \longrightarrow v_{1} \longrightarrow \ldots \longrightarrow v_{N}
$$

From (4.9) and (4.12), we have the next representation: for $x \in X^{0}$

$$
V[x]=\min _{j \in \mathbf{I}(\overline{1, N})} \min _{z \in \mathbb{M}_{j}}\left[\mathbf{c}\left(x, \operatorname{pr}_{1}(z), \overline{1, N}\right)+c_{j}(z, \overline{1, N})+v_{N-1}\left(\operatorname{pr}_{2}(z), \overline{1, N} \backslash\{j\}\right)\right] .
$$

So, by (4.13) and (4.14) we construct the value function $V[\cdot]$; this function realizes the global extremum $\mathbb{V}$.

Algorithm for construction of $V[\cdot]$. By (4.12)-(4.14) we can realize $V[\cdot]$ using the DP procedure with overwriting layers of the Bellman function. So, we have $v_{0}$ defined in terms of $f$. Let $s \in \overline{1, N}$ and $v_{s-1} \in \mathcal{R}_{+}\left[D_{s-1}\right]$ be already constructed. Then we construct $v_{s} \in \mathcal{R}_{+}\left[D_{s}\right]$ by the rule (4.12) using only the function $v_{s-1}$. If $s=N$, then we have the value function $V[\cdot]$ (in this case, (4.12) is reduced to (4.14)): in this case our procedure is completed. If $s<N$, then we replace $v_{s-1}$ by $v_{s}$; the function $v_{s-1}$ (the Bellman function layer) is destroyed. So, in the computer memory, only one of the functions $v_{0}, v_{1}, \ldots, v_{N-1}$ is available (in this connection, we recall investigation [15]). 


\section{§. Optimization of the starting point}

So, we obtain the Bellman procedure for construction of the value function $V[\cdot]$. By this function, the global extremum $\mathbb{V}$ can be determinated. Of course, it is possible the case $V[x]>$ $\mathbb{V} \forall x \in X^{0}$ (we recall that the set $X^{0}$ is not necessarily finite). But some useful particular cases can be chosen. Of course, the simplest case corresponds to variant when

$$
X^{0} \in \operatorname{Fin}(X) .
$$

From (4.10) and (5.1), we obtain that

$$
\mathbb{V}=\min _{x \in X^{0}} v_{N}(x, \overline{1, N})
$$

and SOL $\neq \emptyset$. Indeed, by (5.1) and (5.2) for some $x^{0} \in X^{0}$, we obtain that $V\left[x^{0}\right]=\mathbb{V}=$ $v_{N}\left(x^{0}, \overline{1, N}\right)$. By $(2.15),(\operatorname{sol})\left[x^{0}\right] \neq \emptyset$. We choose $\left(\alpha^{0},\left(z_{t}^{0}\right)_{t \in \overline{0, N}}\right) \in(\operatorname{sol})\left[x^{0}\right]$ and obtain

$$
\mathfrak{G}_{\alpha^{0}}\left[\left(z_{t}^{0}\right)_{t \in \overline{0, N}}\right]=\mathbb{V}
$$

where $\left(\alpha^{0},\left(z_{t}^{0}\right)_{t \in \overline{0, N}}, x^{0}\right) \in \mathbf{D}$ by (2.11) and (2.15). From (2.18) and (5.3), we have the required property

$$
\left(\alpha^{0},\left(z_{t}^{0}\right)_{t \in \overline{0, N}}, x^{0}\right) \in \text { SOL. }
$$

We note that the scheme connected with (5.1)-(5.4) defines a solution near to optimal one in very general case when (5.1) is violated. Now we consider such situation.

So, we suppose until the end of this section that $X^{0} \in \mathcal{P}^{\prime}(X)$ (we return to the general case of $X^{0}$ in Section 2) is equipped with a metric

$$
\rho: X^{0} \times X^{0} \longrightarrow \mathbb{R}_{+}
$$

So, $\left(X^{0}, \rho\right)$ is a metric space. In the following, it is supposed that $\forall \varepsilon \in \mathbb{R}_{+} \backslash\{0\} \exists \delta \in \mathbb{R}_{+} \backslash\{0\}$ $\forall x_{1} \in X^{0} \forall x_{2} \in X^{0}$

$$
\left(\rho\left(x_{1}, x_{2}\right)<\delta\right) \Rightarrow\left(\left|\mathbf{c}\left(x_{1}, y, \overline{1, N}\right)-\mathbf{c}\left(x_{2}, y, \overline{1, N}\right)\right|<\varepsilon \forall y \in \bigcup_{i=1}^{N} \mathfrak{M}_{i}\right) .
$$

So, by (5.5), the functional set

$$
\left\{\mathbf{c}(\cdot, y, \overline{1, N}): y \in \bigcup_{i=1}^{N} \mathfrak{M}_{i}\right\}
$$

is equipotentially uniformly continuous on $\left(X^{0}, \rho\right)$.

Prop o s ition 5.1. The function

$$
v_{N}(\cdot, \overline{1, N})=\left(v_{N}(x, \overline{1, N})\right)_{x \in X^{0}} \in \mathcal{R}_{+}\left[X^{0}\right]
$$

is uniformly continuous, i.e., $\forall \varepsilon \in \mathbb{R}_{+} \backslash\{0\} \exists \delta \in \mathbb{R}_{+} \backslash\{0\} \forall x_{1} \in X^{0} \forall x_{2} \in X^{0}$

$$
\left(\rho\left(x_{1}, x_{2}\right)<\delta\right) \Rightarrow\left(\left|v_{N}\left(x_{1}, \overline{1, N}\right)-v_{N}\left(x_{2}, \overline{1, N}\right)\right|<\varepsilon\right) .
$$

Proof. Fix $\varepsilon_{0} \in \mathbb{R}_{+} \backslash\{0\}$. Using (5.5), we choose $\delta_{0} \in \mathbb{R}_{+} \backslash\{0\}$ for which $\forall x_{1} \in X^{0}$ $\forall x_{2} \in X^{0}$

$$
\left(\rho\left(x_{1}, x_{2}\right)<\delta_{0}\right) \Rightarrow\left(\left|\mathbf{c}\left(x_{1}, y, \overline{1, N}\right)-\mathbf{c}\left(x_{2}, y, \overline{1, N}\right)\right|<\varepsilon_{0} \quad \forall y \in \bigcup_{i=1}^{N} \mathfrak{M}_{i}\right)
$$


Fix $x^{\prime} \in X^{0}$ and $x^{\prime \prime} \in X^{0}$ for which $\rho\left(x^{\prime}, x^{\prime \prime}\right)<\delta_{0}$. Then by (5.7)

$$
\left|\mathbf{c}\left(x^{\prime}, y, \overline{1, N}\right)-\mathbf{c}\left(x^{\prime \prime}, y, \overline{1, N}\right)\right|<\varepsilon_{0} \quad \forall y \in \bigcup_{i=1}^{N} \mathfrak{M}_{i} .
$$

From (4.9) and (4.14), we have the equalities

$$
\begin{aligned}
v_{N}\left(x^{\prime}, \overline{1, N}\right) & =\min _{j \in \mathbf{I}(\overline{1, N})} \min _{z \in \mathbb{M}_{j}}\left[\mathbf{c}\left(x^{\prime}, \operatorname{pr}_{1}(z), \overline{1, N}\right)+c_{j}(z, \overline{1, N})+v\left(\operatorname{pr}_{2}(z), \overline{1, N} \backslash\{j\}\right)\right], \\
v_{N}\left(x^{\prime \prime}, \overline{1, N}\right) & =\min _{j \in \mathbf{I}(\overline{1, N})} \min _{z \in \mathbb{M}_{j}}\left[\mathbf{c}\left(x^{\prime \prime}, \operatorname{pr}_{1}(z), \overline{1, N}\right)+c_{j}(z, \overline{1, N})+v\left(\operatorname{pr}_{2}(z), \overline{1, N} \backslash\{j\}\right)\right] .
\end{aligned}
$$

Let $t^{\prime} \in \mathbf{I}(\overline{1, N})$ and $z^{\prime} \in \mathbb{M}_{t^{\prime}}$ realize (see (5.9)) the equality

$$
v_{N}\left(x^{\prime}, \overline{1, N}\right)=\mathbf{c}\left(x^{\prime}, \operatorname{pr}_{1}\left(z^{\prime}\right), \overline{1, N}\right)+c_{t^{\prime}}\left(z^{\prime}, \overline{1, N}\right)+v\left(\operatorname{pr}_{2}\left(z^{\prime}\right), \overline{1, N} \backslash\left\{t^{\prime}\right\}\right) .
$$

In addition, let $t^{\prime \prime} \in \mathbf{I}(\overline{1, N})$ and $z^{\prime \prime} \in \mathbb{M}_{t^{\prime \prime}}$ (see (5.10)) satisfy the condition

$$
v_{N}\left(x^{\prime \prime}, \overline{1, N}\right)=\mathbf{c}\left(x^{\prime \prime}, \operatorname{pr}_{1}\left(z^{\prime \prime}\right), \overline{1, N}\right)+c_{t^{\prime \prime}}\left(z^{\prime \prime}, \overline{1, N}\right)+v\left(\operatorname{pr}_{2}\left(z^{\prime \prime}\right), \overline{1, N} \backslash\left\{t^{\prime \prime}\right\}\right) .
$$

Hence (see (5.9)), we have, in particular, that

$$
v_{N}\left(x^{\prime}, \overline{1, N}\right) \leqslant \mathbf{c}\left(x^{\prime}, \operatorname{pr}_{1}\left(z^{\prime \prime}\right), \overline{1, N}\right)+c_{t^{\prime \prime}}\left(z^{\prime \prime}, \overline{1, N}\right)+v\left(\operatorname{pr}_{2}\left(z^{\prime \prime}\right), \overline{1, N} \backslash\left\{t^{\prime \prime}\right\}\right) .
$$

Similarly, from (5.10), it follows that

$$
v_{N}\left(x^{\prime \prime}, \overline{1, N}\right) \leqslant \mathbf{c}\left(x^{\prime \prime}, \operatorname{pr}_{1}\left(z^{\prime}\right), \overline{1, N}\right)+c_{t^{\prime}}\left(z^{\prime}, \overline{1, N}\right)+v\left(\operatorname{pr}_{2}\left(z^{\prime}\right), \overline{1, N} \backslash\left\{t^{\prime}\right\}\right) .
$$

From (5.8) and (5.13), we obtain that

$$
v_{N}\left(x^{\prime}, \overline{1, N}\right)<c\left(x^{\prime \prime}, \operatorname{pr}_{1}\left(z^{\prime \prime}\right), \overline{1, N}\right)+c_{t^{\prime \prime}}\left(z^{\prime \prime}, \overline{1, N}\right)+v\left(\operatorname{pr}_{2}\left(z^{\prime \prime}\right), \overline{1, N} \backslash\left\{t^{\prime \prime}\right\}\right)+\varepsilon_{0}
$$

(in (5.15) we take into account that according to (2.6)

$$
\operatorname{pr}_{1}\left(z^{\prime \prime}\right) \in \bigcup_{i=1}^{N} \mathfrak{M}_{i}
$$

but then $\left.\left|\mathbf{c}\left(x^{\prime}, \operatorname{pr}_{1}\left(z^{\prime \prime}\right), \overline{1, N}\right)-\mathbf{c}\left(x^{\prime \prime}, \operatorname{pr}_{1}\left(z^{\prime \prime}\right), \overline{1, N}\right)\right|<\varepsilon_{0}\right)$. From (5.12) and (5.15), it follows that

$$
v_{N}\left(x^{\prime}, \overline{1, N}\right)<v_{N}\left(x^{\prime \prime}, \overline{1, N}\right)+\varepsilon_{0} .
$$

Further, we note that (see (2.6))

$$
\operatorname{pr}_{1}\left(z^{\prime}\right) \in \bigcup_{i=1}^{N} \mathfrak{M}_{i}
$$

but then, by virtue (5.8),

$$
\left|\mathbf{c}\left(x^{\prime}, \operatorname{pr}_{1}\left(z^{\prime}\right), \overline{1, N}\right)-\mathbf{c}\left(x^{\prime \prime}, \operatorname{pr}_{1}\left(z^{\prime}\right), \overline{1, N}\right)\right|<\varepsilon_{0} .
$$

Therefore, it follows from (5.14) and (5.17), that

$$
v_{N}\left(x^{\prime \prime}, \overline{1, N}\right)<c\left(x^{\prime}, \operatorname{pr}_{1}\left(z^{\prime}\right), \overline{1, N}\right)+c_{t^{\prime}}\left(z^{\prime}, \overline{1, N}\right)+v\left(\operatorname{pr}_{2}\left(z^{\prime}\right), \overline{1, N} \backslash\left\{t^{\prime}\right\}\right)+\varepsilon_{0} .
$$

Thus, from (5.11) and (5.18), it follows that

$$
v_{N}\left(x^{\prime \prime}, \overline{1, N}\right)<v_{N}\left(x^{\prime}, \overline{1, N}\right)+\varepsilon_{0} .
$$


From (5.16) and (5.19), it follows that

$$
\left|v_{N}\left(x^{\prime}, \overline{1, N}\right)-v_{N}\left(x^{\prime \prime}, \overline{1, N}\right)\right|<\varepsilon_{0} .
$$

So, the following implication is established

$$
\left(\rho\left(x^{\prime}, x^{\prime \prime}\right)<\delta_{0}\right) \Rightarrow\left(\left|v_{N}\left(x^{\prime}, \overline{1, N}\right)-v_{N}\left(x^{\prime \prime}, \overline{1, N}\right)\right|<\varepsilon_{0}\right) .
$$

Since the choice of $x^{\prime}, x^{\prime \prime}$ was arbitrary, the required property (5.6) is fulfilled.

C o r o 11 a ry 5.1. If $\left(X^{0}, \rho\right)$ is a compact metric space, then

$$
\exists x^{0} \in X^{0}: v_{N}\left(x^{0}, \overline{1, N}\right)=V\left[x^{0}\right]=\mathbb{V} .
$$

P r o o f. Let $\left(X^{0}, \rho\right)$ be a compact metric space. Then topology $\tau^{0}$ of the set $X^{0}$ generated by $\rho$ transforms $X^{0}$ in a metrizable compactum. By Proposition 5.1 the function $v_{N}(\cdot, \overline{1, N})$ is continuous (on $\left(X^{0}, \tau^{0}\right)$ ). By Weierstrass theorem, the function $v_{N}(\cdot, \overline{1, N})$ attains minimum on $X^{0}$. Therefore, by (4.9) and (4.10), we obtain the property (5.21).

We introduce open balls: for $x \in X^{0}$ and $\varepsilon \in \mathbb{R}_{+} \backslash\{\emptyset\}$, we suppose that

$$
B_{\rho}^{0}(x, \varepsilon) \triangleq\left\{y \in X^{0} \mid \rho(x, y)<\varepsilon\right\} .
$$

In the following (in this section), we suppose that $X^{0}$ is a totally bounded set, i.e.,

$$
\forall \varepsilon \in \mathbb{R}_{+} \backslash\{0\} \quad \exists K \in \operatorname{Fin}\left(X^{0}\right): X^{0} \subset \bigcup_{x \in K} B_{\rho}^{0}(x, \varepsilon) .
$$

We note that for every $K \in \operatorname{Fin}\left(X^{0}\right)$, it is defined the value

$$
\min _{x \in K} v_{N}(x, \overline{1, N}) \in \mathbb{R}_{+} .
$$

Proposition 5.2. If $\varepsilon \in \mathbb{R}_{+} \backslash\{0\}$, then

$$
\exists K \in \operatorname{Fin}\left(X^{0}\right): \min _{x \in K} v_{N}(x, \overline{1, N})<\mathbb{V}+\varepsilon .
$$

Pro o f. Let $\varepsilon_{0} \in \mathbb{R}_{+} \backslash\{0\}$. Using Proposition 5.1, we choose $\delta_{0} \in \mathbb{R}_{+} \backslash\{0\}$ for which $\forall x_{1} \in X^{0} \forall x_{2} \in X^{0}$

$$
\left(\rho\left(x_{1}, x_{2}\right)<\delta_{0}\right) \Rightarrow\left(\left|v_{N}\left(x_{1}, \overline{1, N}\right)-v_{N}\left(x_{2}, \overline{1, N}\right)\right|<\frac{\varepsilon_{0}}{2}\right) .
$$

By (5.23), for some $\mathbb{K} \in \operatorname{Fin}\left(X^{0}\right)$, the equality

$$
X^{0}=\bigcup_{x \in \mathbb{K}} B_{\rho}^{0}\left(x, \delta_{0}\right)
$$

holds. By (2.17), we obtain that

$$
V\left[x^{0}\right]<\mathbb{V}+\frac{\varepsilon_{0}}{2}
$$

for some $x^{0} \in X^{0}$. Using (5.25), we obtain that $x^{0} \in B_{\rho}^{0}\left(x^{*}, \delta_{0}\right)$ for some $x^{*} \in \mathbb{K}$. Then $\rho\left(x^{0}, x^{*}\right)<\delta_{0}$ and, by (5.24),

$$
\left|v_{N}\left(x^{0}, \overline{1, N}\right)-v_{N}\left(x^{*}, \overline{1, N}\right)\right|<\frac{\varepsilon_{0}}{2} .
$$

In addition, by (4.9) $V\left[x^{0}\right]=v_{N}\left(x^{0}, \overline{1, N}\right)$. Therefore, by (5.26) and (5.27), the inequality

$$
v_{N}\left(x^{*}, \overline{1, N}\right)<\mathbb{V}+\varepsilon_{0}
$$

holds. By the choice of $x^{*}$,

$$
\min _{x \in \mathbb{K}} v_{N}(x, \overline{1, N}) \leqslant v_{N}\left(x^{*}, \overline{1, N}\right) .
$$

As a corollary, we obtain the required inequality: $\min _{x \in \mathbb{K}} v_{N}(x, \overline{1, N})<\mathbb{V}+\varepsilon_{0}$. 


\section{§ 6. Optimal solutions}

Now, we suppose that procedure (4.13) was realized and we have all functions $v_{0}, v_{1}, \ldots, v_{N}$. Now, we very briefly consider the question about construction of the optimal solution of the problem (2.14). So, we choose $x_{0} \in X^{0}$ for which $v_{N}\left(x_{0}, \overline{1, N}\right) \approx \mathbb{V}$ (in the case of compact metric space $\left(X^{0}, \rho\right)$, we can suppose that $v_{N}\left(x_{0}, \overline{1, N}\right)=\mathbb{V}$; in this case, by the following procedure we obtain an element of SOL (2.18)). Now, we consider the procedure for construction of solution from $(\mathrm{sol})\left[x_{0}\right]$.

So, we suppose that $\mathbf{z}^{(0)} \triangleq\left(x_{0}, x_{0}\right)$. Now, we use (4.14) for $x=x_{0}$ (we recall that $v_{N}\left(x_{0}, \overline{1, N}\right)=V\left[x_{0}\right]$ by (4.9)). Namely, we choose $\eta_{1} \in \mathbf{I}(\overline{1, N})$ and $\mathbf{z}^{(1)} \in \mathbb{M}_{\eta_{1}}$ for which the next equality holds:

$$
v_{N}\left(x_{0}, \overline{1, N}\right)=\mathbf{c}\left(x_{0}, \operatorname{pr}_{1}\left(\mathbf{z}^{(1)}\right), \overline{1, N}\right)+c_{\eta_{1}}\left(\mathbf{z}^{(1)}, \overline{1, N}\right)+v_{N-1}\left(\operatorname{pr}_{2}\left(\mathbf{z}^{(1)}\right), \overline{1, N} \backslash\left\{\eta_{1}\right\}\right) .
$$

Of course, from (4.11), the inclusion $\left(\operatorname{pr}_{2}\left(\mathbf{z}^{(1)}\right), \overline{1, N} \backslash\left\{\eta_{1}\right\}\right) \in D_{N-1}$ follows and the expression in right side of (6.1) is defined correctly. By (4.12)

$$
\begin{gathered}
v_{N-1}\left(\operatorname{pr}_{2}\left(\mathbf{z}^{(1)}\right), \overline{1, N} \backslash\left\{\eta_{1}\right\}\right)=\min _{j \in \mathbf{I}\left(\overline{1, N} \backslash\left\{\eta_{1}\right\}\right)} \min _{z \in \mathbb{M}_{j}}\left[\mathbf{c}\left(\operatorname{pr}_{2}\left(\mathbf{z}^{(1)}\right), \operatorname{pr}_{1}(z), \overline{1, N} \backslash\left\{\eta_{1}\right\}\right)+\right. \\
\left.+c_{j}\left(z, \overline{1, N} \backslash\left\{\eta_{1}\right\}\right)+v_{N-2}\left(\operatorname{pr}_{2}(z), \overline{1, N} \backslash\left\{\eta_{1} ; j\right\}\right)\right] .
\end{gathered}
$$

Using (6.2), we choose $\eta_{2} \in \mathbf{I}\left(\overline{1, N} \backslash\left\{\eta_{1}\right\}\right)$ and $\mathbf{z}^{(2)} \in \mathbb{M}_{\eta_{2}}$ such that

$$
\begin{gathered}
v_{N-1}\left(\operatorname{pr}_{2}\left(\mathbf{z}^{(1)}\right), \overline{1, N} \backslash\left\{\eta_{1}\right\}\right)=\mathbf{c}\left(\operatorname{pr}_{2}\left(\mathbf{z}^{(1)}\right), \operatorname{pr}_{1}\left(\mathbf{z}^{(2)}\right), \overline{1, N} \backslash\left\{\eta_{1}\right\}\right)+ \\
+c_{\eta_{2}}\left(\mathbf{z}^{(2)}, \overline{1, N} \backslash\left\{\eta_{1}\right\}\right)+v_{N-2}\left(\operatorname{pr}_{2}\left(\mathbf{z}^{(2)}\right), \overline{1, N} \backslash\left\{\eta_{1} ; \eta_{2}\right\}\right) .
\end{gathered}
$$

By (4.11), $\left(\operatorname{pr}_{2}\left(\mathbf{z}^{(2)}\right), \overline{1, N} \backslash\left\{\eta_{1} ; \eta_{2}\right\}\right) \in D_{N-2}$. From (6.1) and (6.3), we obtain that

$$
\begin{aligned}
& v_{N}\left(x_{0}, \overline{1, N}\right)=\mathbf{c}\left(x_{0}, \operatorname{pr}_{1}\left(\mathbf{z}^{(1)}\right), \overline{1, N}\right)+\mathbf{c}\left(\operatorname{pr}_{2}\left(\mathbf{z}^{(1)}\right), \operatorname{pr}_{1}\left(\mathbf{z}^{(2)}\right), \overline{1, N} \backslash\left\{\eta_{1}\right\}\right)+ \\
& +c_{\eta_{1}}\left(\mathbf{z}^{(1)}, \overline{1, N}\right)+c_{\eta_{2}}\left(\mathbf{z}^{(2)}, \overline{1, N} \backslash\left\{\eta_{1}\right\}\right)+v_{N-2}\left(\operatorname{pr}_{2}\left(\mathbf{z}^{(2)}\right), \overline{1, N} \backslash\left\{\eta_{1} ; \eta_{2}\right\}\right)
\end{aligned}
$$

(if $N=2$, the optimal solution is already constructed; see (6.4)). Next constructions are similar to (6.1) and (6.3); they should continue until exhaustion of the index set $\overline{1, N}$. By these constructions, an admissible solution $\left(\eta,\left(\mathbf{z}^{(j)}\right)_{j \in \overline{0, N}}\right) \in \tilde{\mathbf{D}}\left[x_{0}\right]$ with the property

$$
\mathfrak{C}_{\eta}\left[\left(\mathbf{z}^{(j)}\right)_{j \in \overline{0, N}}\right]=V\left[x_{0}\right]
$$

will be constructed; from (2.15) and (6.5), we obtain the property

$$
\left(\eta,\left(\mathbf{z}^{(j)}\right)_{j \in \overline{0, N}}\right) \in(\mathrm{sol})\left[x_{0}\right] .
$$

We recall that in given procedure, all functions $v_{1}, \ldots, v_{N}$ should be saved in the computer memory (we keep in mind the scheme (4.13)).

$\mathrm{R}$ e m a rk 6.1. Now we note one typical case: the set $X$ is equipped with a metric $d \in \mathcal{R}_{+}[X \times X]$ and the metric $\rho$ is the constriction of $d$ on $X^{0} \times X^{0}$, i.e., $\rho\left(x_{1}, x_{2}\right) \triangleq d\left(x_{1}, x_{2}\right) \forall x_{1} \in X^{0} \forall x_{2} \in X^{0}$. So, $\left(X^{0}, \rho\right)$ is a subspace of $(X, d)$. Let $w \in \mathbb{R}_{+} \backslash\{0\}$ and the selection of the function $\mathbf{c}$ be defined by the following rule:

$$
\mathbf{c}\left(x_{1}, x_{2}, \overline{1, N}\right)=\frac{d\left(x_{1}, x_{2}\right)}{w} \quad \forall x_{1} \in \mathbf{X} \quad \forall x_{2} \in \tilde{\mathbb{X}}
$$

Then, by the triangle inequality, we have that for $x^{\prime} \in \mathbf{X}, x^{\prime \prime} \in \mathbf{X}$, and $y \in \bigcup_{i=1}^{N} \mathfrak{M}_{i}$,

$$
\left|\mathbf{c}\left(x^{\prime}, y, \overline{1, N}\right)-\mathbf{c}\left(x^{\prime \prime}, y, \overline{1, N}\right)\right|=\frac{1}{w}\left|d\left(x^{\prime}, y\right)-d\left(x^{\prime \prime}, y\right)\right| \leqslant \frac{1}{w} d\left(x^{\prime}, x^{\prime \prime}\right)=\frac{1}{w} \rho\left(x^{\prime}, x^{\prime \prime}\right) ;
$$

so, we obtain that (5.5) is fulfilled. We note that (6.6) corresponds to variant of the metric routing problems; this variant is widely used in problems of discrete optimization. In addition, $w$ can be considered as a velocity; then $\mathbf{c}\left(x_{1}, x_{2}, \overline{1, N}\right)$ corresponds to time for permutation from $x_{1}$ to $x_{2}$. 


\section{$\S 7$. The case when terminal function depends on initial state}

Now, we consider the setting that is a generalization of the problem for which the return to the initial state (starting point) is required. In TSP, this situation is typical: usually, closed TSP is considered. We suppose (see [4]) more general variant: the terminal function depends on the initial state $x \in X^{0}$. Then, our DP procedure is essentially complicated. Namely, for determination of the global extermum, the corresponding DP procedure is required for every $\tilde{x} \in X^{0}$. Namely, in the following, we suppose that

$$
\mathbf{f} \in \mathcal{R}_{+}\left[\mathbf{X} \times X^{0}\right]
$$

In the case of the metric initial problem (we keep in mind the variant when cost functions are defined as distances between points), the natural concrete variant of (7.1) is defined by distance from $x \in \mathrm{X}$ to $x^{0} \in X^{0}$. This concrete definition can corresponds to natural requirement the return to the starting point.

For $x^{0} \in X^{0}$, the use of $\mathbf{f}\left(\cdot, x^{0}\right) \triangleq\left(\mathbf{f}\left(\bar{x}, x^{0}\right)\right)_{\bar{x} \in \mathbf{X}}$ as $f$ does not complicate the setting the problem (2.14), where $x=x^{0}$. For this special case $f=\mathbf{f}\left(\cdot, x^{0}\right)$, we can use the DP procedure corresponding to $[3,11-13]$. In addition, the starting point $x^{0}$ is a parameter. For completeness of our presentation, we absolutely briefly recall the corresponding DP procedure for fixed starting point $x^{0} \in X^{0}$; namely, we consider (2.14) under $f=\mathbf{f}\left(\cdot, x^{0}\right)$. So, for $\left(\alpha,\left(z_{t}\right)_{t \in \overline{0, N}}\right) \in \tilde{\mathbf{D}}\left[x^{0}\right]$, we use

$$
\begin{gathered}
\hat{\mathfrak{C}}_{\alpha}^{0}\left[\left(z_{t}\right)_{t \in \overline{0, N}} \mid x^{0}\right] \triangleq \sum_{t=1}^{N}\left[\mathbf{c}\left(\operatorname{pr}_{2}\left(z_{t-1}\right), \operatorname{pr}_{1}\left(z_{t}\right), \alpha^{1}(\overline{t, N})\right)+\right. \\
\left.+c_{\alpha(t)}\left(z_{t}, \alpha^{1}(\overline{t, N})\right)\right]+\mathbf{f}\left(\operatorname{pr}_{2}\left(z_{N}\right), x^{0}\right)
\end{gathered}
$$

for estimation of $\left(\alpha,\left(z_{t}\right)_{t \in \overline{0, N}}\right)$; of course, (7.2) coincides with $\mathfrak{C}_{\alpha}\left[\left(z_{t}\right)_{t \in \overline{0, N}}\right]$ of (2.13) for $f=$ $\mathbf{f}\left(\cdot, x^{0}\right)$. Then

$$
\hat{\mathfrak{C}}_{\alpha}^{0}\left[\left(z_{t}\right)_{t \in \overline{0, N}} \mid x^{0}\right] \longrightarrow \min , \quad\left(\alpha,\left(z_{t}\right)_{t \in \overline{0, N}}\right) \in \tilde{\mathbf{D}}\left[x^{0}\right]
$$

corresponds to the problem (2.14) under $x=x^{0}$ and above-mentioned variant of $f$. As a corollary,

$$
\mathbf{V}\left[x^{0}\right] \triangleq \min _{\left(\alpha,\left(z_{t}\right)_{t \in \overline{0, N}}\right) \in \tilde{\mathbf{D}}\left[x^{0}\right]} \hat{\mathfrak{C}}_{\alpha}^{0}\left[\left(z_{t}\right)_{t \in \overline{0, N}} \mid x^{0}\right] \in \mathbb{R}_{+}
$$

is $V\left[x^{0}\right]$ for our case connected with (7.1). Moreover,

$$
(\mathrm{Sol})\left[x^{0}\right] \triangleq\left\{\left(\alpha^{0},\left(z_{t}^{0}\right)_{t \in \overline{0, N}}\right) \in \tilde{\mathbf{D}}\left[x^{0}\right] \mid \hat{\mathfrak{C}}_{\alpha^{0}}^{0}\left[\left(z_{t}^{0}\right)_{t \in \overline{0, N}} \mid x^{0}\right]=\mathbf{V}\left[x^{0}\right]\right\} \in \mathcal{P}^{\prime}\left(\tilde{\mathbf{D}}\left[x^{0}\right]\right)
$$

is the concrete variant of $(\mathrm{sol})\left[x^{0}\right](2.15)$. For solving the problem (7.3), we use the special DP procedure of attachment to $x^{0}$. Of course, this $x^{0}$-procedure corresponds essentially to constructions of Section 4 (we keep in mind (4.2)-(4.8)).

In addition, the Bellman function

$$
\mathbf{v}\left[x^{0}\right] \in \mathcal{R}_{+}\left[\left(\left\{x^{0}\right\} \bigcup\left(\bigcup_{i=1}^{N} \mathbf{M}_{i}\right)\right) \times \mathcal{P}(\overline{1, N})\right]
$$

is defined similarly to [14, Section 4]. Also, as in [14, Section 4], we construct the layers $\mathbf{v}_{0}\left[x^{0}\right]$, $\mathbf{v}_{1}\left[x^{0}\right], \ldots$, and $\mathbf{v}_{N}\left[x^{0}\right]$ of the function $\mathbf{v}\left[x^{0}\right]$. In addition, $\mathbf{v}_{s}\left[x^{0}\right] \in \mathcal{R}_{+}\left[D_{s}\right]$ under $s \in \overline{1, N}$; we note that $D_{s}$ is defined as in Section 4 under $s<N$. The set $D_{N}$ is replaced by singleton $\left\{\left(x^{0}, \overline{1, N}\right)\right\}$ and $\mathbf{v}_{N}\left[x^{0}\right] \in \mathcal{R}_{+}\left[\left\{\left(x^{0}, \overline{1, N}\right)\right\}\right]$. In addition,

$$
\mathbf{v}_{0}\left[x^{0}\right](x, \emptyset)=\mathbf{f}\left(x, x^{0}\right) \quad \forall x \in \tilde{\mathcal{M}}
$$


Later, recurrent procedure of [14, Section 4] is realized. The basic transformation $\mathbf{v}_{s-1}\left[x^{0}\right]$ in $\mathbf{v}_{s}\left[x^{0}\right]$ corresponds to [13]; moreover, see [14, Proposition 4.1]. As a result,

$$
\begin{aligned}
\mathbf{V}\left[x^{0}\right]= & \mathbf{v}_{N}\left[x^{0}\right]\left(x^{0}, \overline{1, N}\right)=\min _{j \in \mathbf{I}(\overline{1, N})} \min _{z \in \mathbb{M}_{j}}\left[\mathbf{c}\left(x^{0}, \operatorname{pr}_{1}(z), \overline{1, N}\right)+\right. \\
& \left.+c_{j}(z, \overline{1, N})+\mathbf{v}_{N-1}\left[x^{0}\right]\left(\operatorname{pr}_{2}(z), \overline{1, N} \backslash\{j\}\right)\right] .
\end{aligned}
$$

Constructible (optimal) solution from the set $(\mathrm{Sol})\left[x^{0}\right]$ is realized similarly to Section 4 . So, (7.5) generalizes the individual DP procedure of attachment to $x^{0}$ (see (7.5)). For determination of the global extremum, we should realize procedures of above-mentioned type for all $x^{0} \in X^{0}$; then we obtain $\mathbf{V}[\cdot] \triangleq(\mathbf{V}[x])_{x \in X^{0}}$ and can determine the greatest lower bound $\mathbf{V}_{\text {opt }}$ of the set $\left\{\mathbf{V}[x]: x \in X^{0}\right\}$. Later, we find $x^{00} \in X^{0}$ with $\mathbf{V}\left[x^{00}\right] \approx \mathbf{v}_{\text {opt }}$ and realize the solving procedure for problem (7.3) under $x^{0}=x^{00}$ (we keep in mind the question about construction of the optimal solution in the form of pair: route-trajectory). So, for the problem of optimization of the starting point under terminal function (7.1), we obtain very complicated total optimal procedure.

Now we consider one decomposition algorithm (see [4]) realizing the upper estimate for $\mathbf{V}_{\text {opt }}$. First, we note that

$$
\mathbf{V}_{\mathrm{opt}} \triangleq \inf _{x \in X^{0}} \mathbf{V}[x]=\inf _{x \in X^{0}} \min _{\left(\alpha,\left(z_{t}\right)_{t \in \overline{0, N}}\right) \in \tilde{\mathbf{D}}[x]} \hat{\mathfrak{C}}_{\alpha}^{0}\left[\left(z_{t}\right)_{t \in \overline{0, N}} \mid x\right] \in \mathbb{R}_{+}
$$

(of course we use (7.4) with obvious replacement $x^{0} \longrightarrow x$ for definition of $\mathbf{V}[x]$ under $x \in X^{0}$ ). We will apply the "unique" DP procedure of Sections 3 and 4 under $f \in \mathcal{R}_{+}[\mathbf{X}]$ defined by the rule

$$
f(x) \triangleq 0 \quad \forall x \in \mathbf{X}
$$

So, we return to settings of Section 2. But, in the following, these settings (see (2.14) and (2.16)) are used as the investigation instrument. Namely, we consider the algorithm at the functional level. For this purpose, we introduce the special designations corresponding to employment of definitions of Sections 3 and 4 under condition (7.7). So, for $\alpha \in \mathbb{P}$ and $\left(z_{t}\right)_{t \in \overline{0, N}} \in \mathbb{Z}$, we suppose that

$$
\tilde{\mathfrak{C}}_{\alpha}\left[\left(z_{t}\right)_{t \in \overline{0, N}}\right] \triangleq \sum_{t=1}^{N}\left[\mathbf{c}\left(\operatorname{pr}_{2}\left(z_{t-1}\right), \operatorname{pr}_{1}\left(z_{t}\right), \alpha^{1}(\overline{t, N})\right)+c_{\alpha(t)}\left(z_{t}, \alpha^{1}(\overline{t, N})\right)\right] .
$$

Then, under $x \in X^{0}$, the our auxiliary problem

$$
\tilde{\mathfrak{C}}_{\alpha}\left[\left(z_{t}\right)_{t \in \overline{0, N}}\right] \longrightarrow \min , \quad\left(\alpha,\left(z_{t}\right)_{t \in \overline{0, N}}\right) \in \tilde{\mathbf{D}}[x]
$$

is a partial case of (2.14) for the case (7.7). We suppose that

$$
\tilde{V}[x] \triangleq \min _{\left(\alpha,\left(z_{t}\right)_{t \in \overline{0, N}}\right) \in \tilde{\mathbf{D}}[x]} \tilde{\mathfrak{C}}_{\alpha}\left[\left(z_{t}\right)_{t \in \overline{0, N}}\right] \in \mathbb{R}_{+}
$$

is the corresponding concrete variant of $V[x]$ from Section 2. Now, we note also the natural connection of (7.2) and (7.8); namely, by (7.2) and (7.8), we obtain that

$$
\hat{\mathfrak{C}}_{\alpha}^{0}\left[\left(z_{t}\right)_{t \in \overline{0, N}} \mid x\right]=\tilde{\mathfrak{C}}_{\alpha}\left[\left(z_{t}\right)_{t \in \overline{0, N}}\right]+\mathbf{f}\left(\operatorname{pr}_{2}\left(z_{N}\right), x\right)
$$

for $\left(\alpha,\left(z_{t}\right)_{t \in \overline{0, N}}\right) \in \tilde{\mathbf{D}}[x]$ (recall that $x \in X^{0}$ ). We note that, by (7.11), the natural decomposition variant of a solution will be found.

Now we introduce the solution set for problem (7.9) (of course, we keep in mind the obvious concrete variant of (2.15)): under $x \in X^{0}$

$$
(\mathbf{s o l})[x] \triangleq\left\{\left(\alpha^{0},\left(z_{t}^{0}\right)_{t \in \overline{0, N}}\right) \in \tilde{\mathbf{D}}[x] \mid \tilde{\mathfrak{C}}_{\alpha^{0}}\left[\left(z_{t}^{0}\right)_{t \in \overline{0, N}}\right]=\tilde{V}[x]\right\} \in \mathcal{P}^{\prime}(\tilde{\mathbf{D}}[x]) .
$$


For determination of the function $\tilde{V}[\cdot]$, we can use the procedure of Section 4 . In addition, we preserve $\mathfrak{G}_{1}, \ldots, \mathfrak{G}_{N}, D_{0}, D_{1}, \ldots, D_{N}$. Later, we construct the required variants of $v_{0}, v_{1}, \ldots, v_{N}$. For these variants, we use designations $\tilde{v}_{0}, \tilde{v}_{1}, \ldots, \tilde{v}_{n}$. In addition, $\tilde{v}_{0} \in \mathcal{R}_{+}\left[D_{0}\right]$ is the function for which $\tilde{v}_{0}(x, \emptyset)=0 \forall x \in \tilde{\mathcal{M}}$. From (4.12), we extract the procedure for transformation $\tilde{v}_{s-1} \longrightarrow \tilde{v}_{s}$ under $s \in \overline{1, N}$ : under $(x, K) \in D_{s}$

$$
\tilde{v}_{s}(x, K)=\min _{j \in \mathbf{I}(K)} \min _{z \in \mathbb{M}_{j}}\left[\mathbf{c}\left(x, \operatorname{pr}_{1}(z), K\right)+c_{j}(z, K)+\tilde{v}_{s-1}\left(\operatorname{pr}_{2}(z), K \backslash\{j\}\right)\right] .
$$

Of course, (7.13) is the variant of (4.12) for the case (7.7). We obtain the recurrent procedure $\tilde{v}_{0} \longrightarrow \tilde{v}_{1} \longrightarrow \ldots \longrightarrow \tilde{v}_{N}$; this procedure is the obvious particular case of (4.13). In addition,

$$
\tilde{V}[x]=\tilde{v}_{N}(x, \overline{1, N}) \forall x \in X^{0} .
$$

So, we have the (unique) DP procedure universal with respect to $x \in X^{0}$. For determination of (optimal) solutions from the sets (7.12), we use the natural procedure of Section 5 (see (6.1)-(6.5) under obvious redefinitions).

Now we return to (7.10). As in [4], we introduce

$$
\mathcal{V}\left(\alpha,\left(z_{t}\right)_{t \in \overline{0, N}}, x\right) \triangleq \tilde{V}[x]+\mathbf{f}\left(\operatorname{pr}_{2}\left(z_{N}\right), x\right) \quad \forall x \in X^{0} \quad \forall\left(\alpha,\left(z_{t}\right)_{t \in \overline{0, N}}\right) \in(\mathbf{s o l})[x] .
$$

Then, by [4, Proposition 4.1], we obtain that

$$
\mathbf{V}[x] \leqslant \mathcal{V}\left(\alpha,\left(z_{t}\right)_{t \in \overline{0, N}}, x\right) \quad \forall x \in X^{0} \forall\left(\alpha,\left(z_{t}\right)_{t \in \overline{0, N}}\right) \in(\mathbf{s o l})[x] .
$$

For employment of (7.16) under the required estimate obtaining, we introduce

$$
\overline{\mathbb{V}} \triangleq \inf _{x \in X^{0}} \min _{\left(\alpha,\left(z_{t}\right)_{t \in \overline{0, N}}\right) \in(\mathbf{s o l})[x]} \mathcal{V}\left(\alpha,\left(z_{t}\right)_{t \in \overline{0, N}}, x\right) \in \mathbb{R}_{+} .
$$

Then, from (2.17), (7.16) and (7.17), the obvious estimate for the global extremum is realized:

$$
\mathbf{V}_{\text {opt }} \leqslant \overline{\mathbb{V}}
$$

Under $X^{0} \in \operatorname{Fin}(X)$, the estimate (7.18) corresponds to use the natural

Decomposition algorithm. Namely, under (7.7), we determine $\left(\mathfrak{G}_{1}, \ldots, \mathfrak{G}_{N}\right)$ and (later)

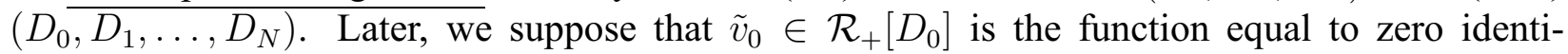
cally.

With this function $\tilde{v}_{0}$, we realize the recurrent procedure

$$
\tilde{v}_{0} \longrightarrow \tilde{v}_{1} \longrightarrow \ldots \longrightarrow \tilde{v}_{N}
$$

in (7.19), $\tilde{v}_{N} \in \mathcal{R}_{+}\left[D_{N}\right]$, where $D_{N}=\left\{(x, \overline{1, N}): x \in X^{0}\right\}$. With this function $\tilde{v}_{N}$, we realize $\tilde{V}[\cdot]$ by (7.14). Later, we determine (sol) $[x]$ for every $x \in X^{0}$; for this, we use the procedure of Section 6 (see (6.1)-(6.5)). Here, we use all functions (7.19). Of course, we can chop up the procedure and determinate only some nonempty subset of (sol) $[x]$ for an arbitrary $x \in X^{0}$. But now, we suppose that all set $(\mathbf{s o l})[x]$ can be constructed for every $x \in X^{0}$; in patricular, this variant is realized by procedure similar to (6.1)-(6.5) in the case when every such set is a singleton. Later, we determine

$$
\tilde{\mathbf{v}}[x] \triangleq \min _{\left(\alpha,\left(z_{t}\right)_{t \in \overline{0, N}}\right) \in(\mathbf{s o l})[x]} \mathcal{V}\left(\alpha,\left(z_{t}\right)_{t \in \overline{0, N}}, x\right) \in \mathbb{R}_{+} \forall x \in X^{0} .
$$

Then, by (7.17) and (7.20), we obtain the equality

$$
\overline{\mathbb{V}}=\inf _{x \in X^{0}} \tilde{\mathbf{v}}[x] .
$$


Recall that now we restrict oneself to the case $X^{0} \in \operatorname{Fin}(X)$. Then, in (7.21), the corresponding minimum is achieved. We solve the problem

$$
\tilde{\mathbf{v}}[x] \longrightarrow \min , \quad x \in X^{0} .
$$

So, we find $\tilde{x}^{0} \in X^{0}$ with the property $\tilde{\mathbf{v}}\left[\tilde{x}^{0}\right]=\overline{\mathbb{V}}$. Later (see (7.20)), we use $\left(\tilde{\alpha}^{0},\left(\tilde{z}_{t}^{0}\right)_{t \in \overline{0, N}}\right) \in$ $(\mathbf{s o l})\left[\tilde{x}^{0}\right]$ for which

$$
\mathcal{V}\left(\tilde{\alpha}^{0},\left(\tilde{z}_{t}^{0}\right)_{t \in \overline{0, N}}, \tilde{x}^{0}\right)=\tilde{\mathbf{v}}\left[\tilde{x}^{0}\right]=\overline{\mathbb{V}} .
$$

(we recall that (sol) $\left[x^{0}\right]$ was defined under the previous step of our algorithm). In addition,

$$
\mathcal{V}\left(\tilde{\alpha}^{0},\left(\tilde{z}_{t}^{0}\right)_{t \in \overline{0, N}}, \tilde{x}^{0}\right)=\hat{\mathfrak{C}}_{\tilde{\alpha}^{0}}^{0}\left[\left(\tilde{z}_{t}^{0}\right)_{t \in \overline{0, N}} \mid \tilde{x}^{0}\right]
$$

R e m a r k 7.1. Now we check (7.23). Indeed, by (7.12), $\left(\tilde{\alpha}^{0},\left(\tilde{z}_{t}^{0}\right)_{t \in \overline{0, N}}\right) \in \tilde{\mathbf{D}}\left[\tilde{x}^{0}\right]$ and, by (7.14),

$$
\tilde{\mathfrak{C}}_{\tilde{\alpha}^{0}}\left[\left(\tilde{z}_{t}^{0}\right)_{t \in \overline{0, N}}\right]=\tilde{V}\left[\tilde{x}^{0}\right]=\tilde{v}_{N}\left(\tilde{x}^{0}, \overline{1, N}\right) .
$$

From (7.11), (7.15), and (7.24), we obtain that

$$
\mathcal{V}\left(\tilde{\alpha}^{0},\left(\tilde{z}_{t}^{0}\right)_{t \in \overline{0, N}}, \tilde{x}^{0}\right)=\tilde{\mathfrak{C}}_{\tilde{\alpha}^{0}}\left[\left(\tilde{z}_{t}^{0}\right)_{t \in \overline{0, N}}\right]+\mathbf{f}\left(\operatorname{pr}_{2}\left(\tilde{z}_{N}^{0}\right), \tilde{x}^{0}\right)=\hat{\mathfrak{C}}_{\alpha}^{0}\left[\left(\tilde{z}_{t}^{0}\right)_{t \in \overline{0, N}} \mid \tilde{x}^{0}\right] .
$$

So, (7.23) is established.

From (7.22) and (7.23), we obtain the following equality:

$$
\hat{\mathfrak{C}}_{\tilde{\alpha}^{0}}^{0}\left[\left(\tilde{z}_{t}^{0}\right)_{t \in \overline{0, N}} \mid \tilde{x}^{0}\right]=\overline{\mathbb{V}} .
$$

In addition, $\left(\tilde{\alpha}^{0},\left(\tilde{z}_{t}^{0}\right)_{t \in \overline{0, N}}, \tilde{x}^{0}\right) \in \mathbf{D}$ realizes the estimate $(7.18)$. We consider $\overline{\mathbb{V}}$ and $\left(\tilde{\alpha}^{0},\left(\tilde{z}_{t}^{0}\right)_{t \in \overline{0, N}}\right.$, $\left.\tilde{x}^{0}\right)$ as a result of our decomposition algorithm, i.e.,

$$
\mathbb{V} \leqslant \hat{\mathfrak{C}}_{\tilde{\alpha}^{0}}^{0}\left[\left(\tilde{z}_{t}^{0}\right)_{t \in \overline{0, N}} \mid \tilde{x}^{0}\right]=\overline{\mathbb{V}}
$$

We recall that in [4] computing experiment showed that, under this decomposition, the loss by result is unessential under perceptible prize in the sense of the calculation time (see $[4, \S 4]$ ).

\section{§ 8. Computational experiment}

Calculations were made on the computer with the Intel i5-2400 processor, 8GB memory, and operating system Windows 7 (64-bit). The program was developed in C++ language with using of Qt library for build user interface.

For motion estimation, in this experiment, cost functions from [14, Section 6] were used. These functions depend on visited megalopolises list and related with engineering restrictions in CNC metal cutting plants. These functions allow to take account termal restrictions. There should be enough metal to ensure the quality of the cut around the finish cut segment. In addition, for both samples, computatuions with heuristic algorithm from [14, Section 6] (greedy and iterative versions) were made. Data on the coordinates of the points for examples are not given by reasons of economy.

Example 1. Number of contours is 35. Number of ordered pairs is 22. Length of the finish cut area is $150 \mathrm{~mm}$ (see [14]). Width of finish cut area is $50 \mathrm{~mm}$. The penalty with value 1000000 was used if $25 \%$ (or more) of finish cut area is covered by holes in metal or out of sheet space.

The starting point was selected from rectangle with corners $(0,0),(0,1500),(1850,1500)$ and $(1850,0)$. The step of point checking was $100 \mathrm{~mm}$.

The obtained result is 80.897 . It is less than penalty value (i.e. 1000000). Therefore, all thermal restrictions have been performed. Penalty was no occurred. The found start point is $(0$, 200). Computational duration is 40 h. 25 min. The route is shown in Fig. 1. 


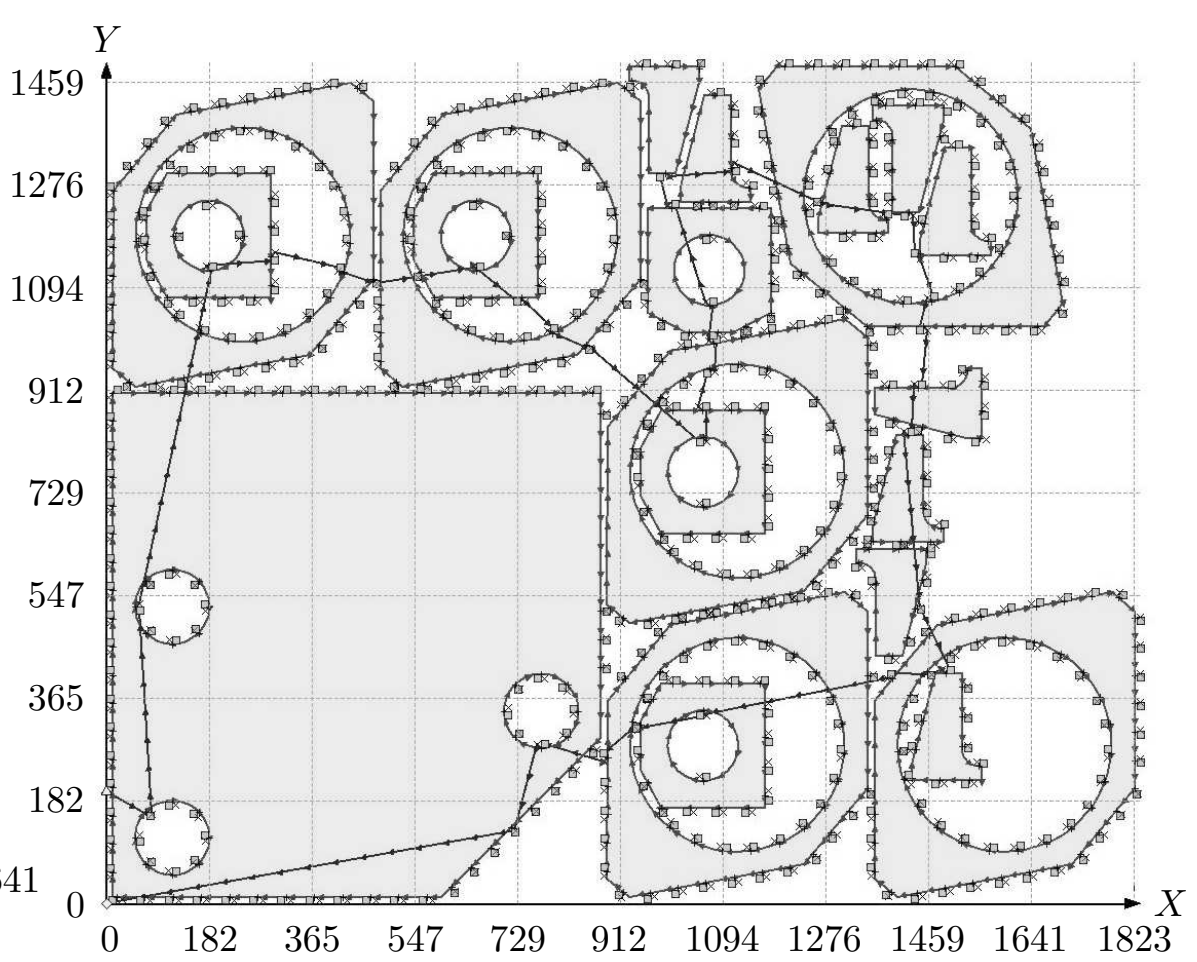

Figure 1. Example 1. Calculated DP results

The greedy algorithm result is 85.167 , computation time is less than 1 second. The iterative heuristic algorithm result is 82.722 , computation time is $5 \mathrm{~min} .38 \mathrm{sec}$. It is very close to the DP result (deviation is $2.26 \%$ ). No penalty found.

Example 2. Number of contours is 35 . Number of ordered pairs is 24. Coordinates of finish point are $(0,0)$. Length of the finish cut area is $150 \mathrm{~mm}$. Width of finish cut area is $50 \mathrm{~mm}$. The penalty with value 1000000 was used if $25 \%$ (or more) of finish cut area is covered by holes in metal or out of sheet space.

The starting point was selected from rectangle with corners $(0,0),(0,2000),(2300,2000)$ and $(2300,0)$. The step of point checking was $10 \mathrm{~mm}$.

The obtained result is 85.508 . Penalty was no occurred. The found start point is $(0,150)$. Computational duration is 84 h. 26 min. The route is shown in Fig. 2.

The greedy algorithm result is 89.431 , computation time is less than 1 second. The iterative heuristic algorithm result is 88.406 , computation time is $6 \mathrm{~min}$. $4 \mathrm{sec}$. It is also close to the DP result (deviation is $3.39 \%$ ). No penalty found.

\section{§. Conclusion}

Calculations confirm the good quality of the iterative algorithm from the article [14] under real constraints for a problem of significant dimension (for the case of smaller dimension, the comparison with the extremum was made in [14, Section 6], where good results are also obtained). This algorithm gives gain in comparison with the greedy algorithm, and it's result is close to the optimal solution. Therefore, the following application of DP is useful: for problems of moderate dimension containing a full complex of constraints, it makes sense to find a global extremum with the aim of testing heuristics for later application in problems of large dimension (see [16]).

Funding. This research was supported by the Russian Foundation for Basic Research (projects no. 17-08-01385). 


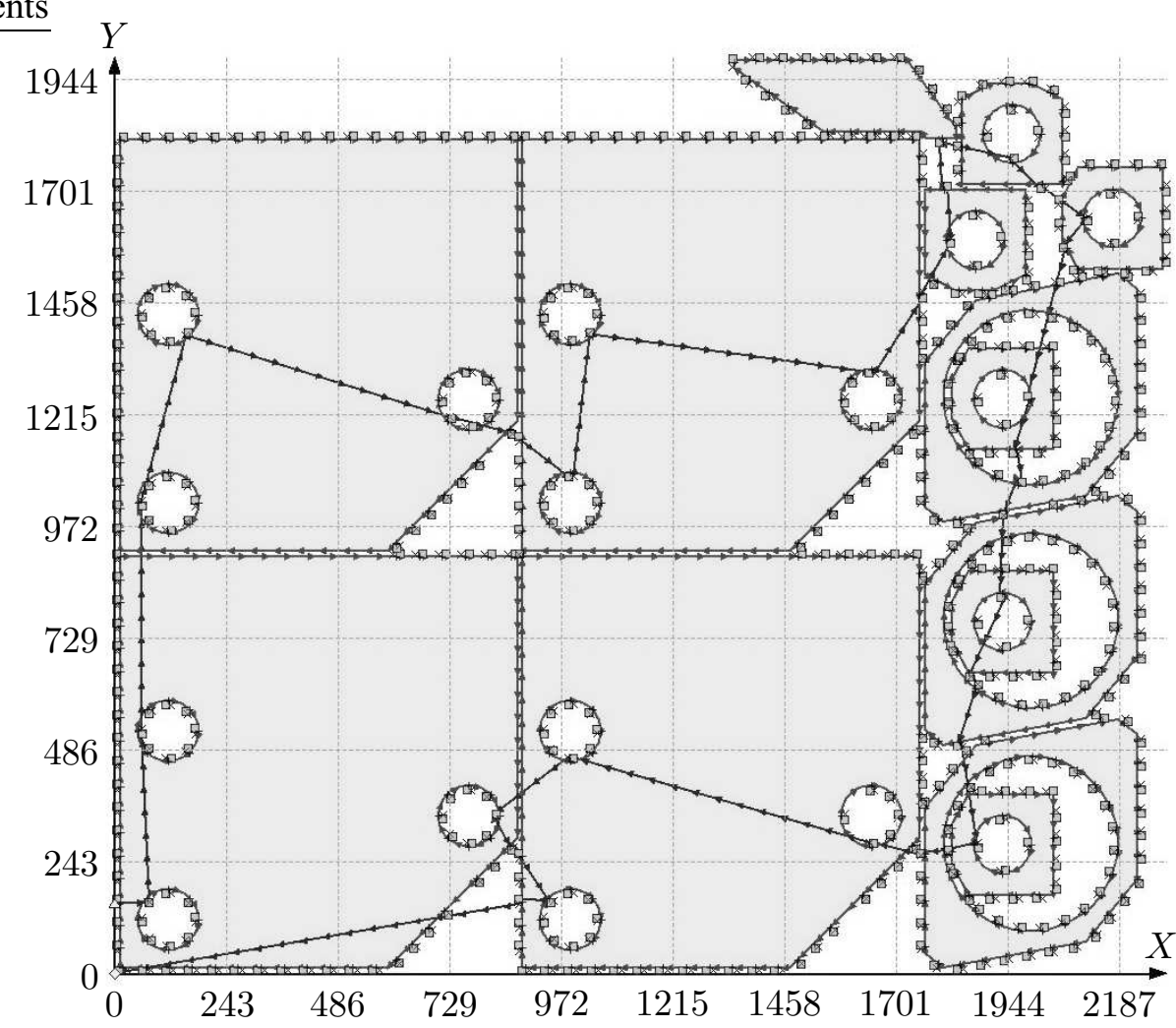

Figure 2. Example 2. Calculated DP results.

\section{REFERENCES}

1. Gutin G., Punnen A. The traveling salesman problem and its variations, Berlin: Springer, 2002.

2. Cook W.J. In pursuit of the traveling salesman. Mathematics at the limits of computation, Princeton, New Jersey: Princeton University Press, 2012.

3. Chentsov A.G., Chentsov P.A. Optimization of the start point in the GTSP with the precedence conditions, Vestnik Yuzhno-Ural'skogo Universiteta. Seriya Matematicheskoe Modelirovanie i Programmirovanie, 2018, vol. 11, issue 2, pp. 83-95 (in Russian). https://doi.org/10.14529/mmp180207

4. Chentsov A.G., Chentsov P.A. On one routing task with the optimization of the start-finish point, Izvestiya Instituta Matematiki i Informatiki Udmurtskogo Gosudarstvennogo Universiteta, 2018, vol. 52, pp. 103-115 (in Russian). https://doi.org/10.20537/2226-3594-2018-52-08

5. Bellman R. Dynamic programming treatment of the travelling salesman problem, Journal of the ACM, 1962, vol. 9, issue 1, pp. 61-63.

6. Held M., Karp R.M. A dynamic programming approach to sequencing problems, Journal of the Society for Industrial and Applied Mathematics, 1962, vol. 10, no. 1, pp. 196-210.

https://doi.org/10.1137/0110015

7. Chentsov A.A., Chentsov A.G., Sesekin A.N. Dynamic programming in a generic bottleneck problem and starting point optimization, Vestnik Udmurtskogo Universiteta. Matematika. Mekhanika. Komp'yuternye Nauki, 2018, vol 28, issue 3, pp. 348-363 (in Russian). https://doi.org/10.20537/vm180306

8. Kuratowski K., Mostowski A. Set theory, Amsterdam: North-Holland Publishing Company, 1967.

9. Dieudonne J. Foundations of modern analysis, New York: Academic Press, 1960.

10. Cormen T., Leiserson C., Rivest R. Introduction to algorithms, Cambridge: MIT Press, 1990.

11. Chentsov A.G. Ekstremal'nye zadachi marshrutizatsii i raspredeleniya zadanii: voprosy teorii (Extremal problems of routing and assignment of tasks: questions of theory), Moscow-Izhevsk: Regular and Chaotic Dynamics, Institute of Computer Science, 2008. 
12. Chentsov A.G. Problem of successive megalopolis traversal with the precedence conditions, Automation and Remote Control, 2014, vol. 75, issue 4, pp. 728-744. https://doi.org/10.1134/S0005117914040122

13. Chentsov A.G. To question of routing of works complexes, Vestnik Udmurtskogo Universiteta. Matematika. Mekhanika. Komp'yuternye Nauki, 2013, issue 1, pp. 59-82 (in Russian). https://doi.org/10.20537/vm130107

14. Chentsov A.G., Chentsov P.A. Routing under constraints: Problem of visit to megalopolises, Automation and Remote Control, 2016, vol. 77, issue 11, pp. 1957-1974. https://doi.org/10.1134/S0005117916110060

15. Lawler E.L. Efficient implementation of dynamic programming algorithms for sequencing problems, CWI. Technical Reports, Stichting Mathematish Centrum, Mathematische Besliskunde, 1979, BW 106/79, pp. 1-16.

16. Chentsov A.G., Chentsov P.A. Dynamic programming and heuristic methods in routing problems, Izvestiya Yuzhnogo Federal'nogo Universiteta. Tekhnicheskie Nauki, 2017, no. 9, pp. 169-181 (in Russian). https://doi.org/10.23683/2311-3103-2017-9-169-181

Received 30.07.2019

Chentsov Aleksandr Georgievich, Doctor of Physics and Mathematics, Corresponding Member, Russian Academy of Science, Chief Researcher, N.N. Krasovskii Institute of Mathematics and Mechanics, Ural Branch of the Russian Academy of Sciences, ul. S. Kovalevskoi, 16, Yekaterinburg, 620219, Russia;

Professor, Institute of Radioelectronics and Information Technologies, Ural Federal University, ul. Mira, 19, Yekaterinburg, 620002, Russia.

E-mail: chentsov@imm.uran.ru

Chentsov Pavel Aleksandrovich, Candidate of Physics and Mathematics, Senior Researcher, Department of Computer Networks, N. N. Krasovskii Institute of Mathematics and Mechanics, Ural Branch of the Russian Academy of Sciences, ul. S. Kovalevskoi, 16, Yekaterinburg, 620219, Russia;

Senior Researcher, Mechanical Engineering Institute, Ural Federal University, ul. Mira, 19, Yekaterinburg, 620002, Russia.

E-mail: chentsov.p@mail.ru

Citation: A. G. Chentsov, P. A. Chentsov. The routing problems with optimization of the starting point: dynamic programming, Izvestiya Instituta Matematiki i Informatiki Udmurtskogo Gosudarstvennogo Universiteta, 2019, vol. 54, pp. 102-121. 


\section{А. Г. Ченцов, П. А. Ченцов \\ Маршрутная задача с оптимизацией стартовой точки: динамическое программирование}

Ключевые слова: маршрутная задача, динамическое программирование, условия предшествования.

УДК: 519.6

DOI: $10.20537 / 2226-3594-2019-54-08$

Рассматривается экстремальная задача маршрутизации, ориентированная на инженерные приложения в машиностроении. Имеется в виду известная задача управления инструментом при листовой резке деталей на машинах с ЧПУ. Используется математическая модель, включающая систему мегаполисов (непустых конечных множеств) и функции стоимости, зависящие от списка заданий. Мегаполисы конструируются на основе дискретизации эквидистант, отвечающих контурам деталей, а зависимость от списка заданий возникает из соображений, связанных с учетом ограничений динамического характера, возникающих по мере выполнения заданий. Среди всех ограничений выделяются условия предшествования (предваряющая резка внутренних контуров детали в сравнении с внешним, более ранняя резка крупных деталей и т.д.). Рациональный учет условий предшествования позволяет в определенной степени снизить сложность вычислений при использовании широко понимаемого динамического программирования (ДП) в реализации, развивающей схему Р.Беллмана. Данный подход позволяет принципиально решать задачу оптимизации комплексов, включающих начальное состояние (точку старта), способ нумерации мегаполисов в порядке их посещения и конкретную траекторию процесса. Для задачи, осложненной зависимостью терминальной функции от начального состояния, используется декомпозиционный алгоритм, позволяющий в существенной части процедуры применять единую (для всех начальных состояний) схему ДП. Оптимальный алгоритм на основе ДП реализован в виде программы для ПЭВМ; проведен вычислительный эксперимент.

Финансирование. Работа выполнена при финансовой поддержке Российского Фонда Фундаментальных Исследований (проект № 17-08-01385).

\section{СПИСОК ЛИТЕРАТУРЫ}

1. Gutin G., Punnen A. The traveling salesman problem and its variations. Berlin: Springer, 2002.

2. Cook W.J. In pursuit of the traveling salesman. Mathematics at the limits of computation. Princeton, New Jersey: Princeton University Press, 2012.

3. Ченцов А.Г., Ченцов П.А. Оптимизация точки старта в задаче последовательного обхода мегаполисов при наличии условий предшествования // Вестн. ЮУрГУ. Сер. Матем. моделирование и программирование. 2018. Т. 11. Вып. 2. С. 83-95.

4. Ченцов А.Г., Ченцов П.А. Об одной задаче маршрутизации с оптимизацией точки стартафиниша // Известия Института математики и информатики Удмуртского государственного университета. 2018. Т. 52. С. 103-115. https://doi.org/10.20537/2226-3594-2018-52-08

5. Bellman R. Dynamic programming treatment of the travelling salesman problem // Journal of the ACM. 1962. Vol. 9. Issue 1. P. 61-63.

6. Held M., Karp R.M. A dynamic programming approach to sequencing problems // Journal of the Society for Industrial and Applied Mathematics. 1962. Vol. 10. No. 1. P. 196-210. https://doi.org/10.1137/0110015

7. Ченцов А.Г., Ченцов А.А., Сесекин А.Н. Динамическое программирование в обобщенной задаче «на узкие места» и оптимизация точки старта // Вестник Удмуртского университета. Математика. Механика. Компьютерные науки. 2018. Т. 28. Вып. 3. С. 348-363.

https://doi.org/10.20537/vm180306

8. Kuratowski K., Mostowski A. Set theory. Amsterdam: North-Holland Publishing Company, 1967.

9. Dieudonne J. Foundations of modern analysis. New York: Academic Press, 1960. 
10. Cormen T., Leiserson C., Rivest R. Introduction to algorithms. Cambridge: MIT Press, 1990.

11. Ченцов А.Г. Экстремальные задачи маршрутизации и распределения заданий: вопросы теории. М.-Ижевск: Регулярная и хаотическая динамика, Ижевский институт компьютерных исследований, 2008.

12. Ченцов А.Г. Задача последовательного обхода мегаполисов с условиями предшествования // Автоматика и телемеханика. 2014. № 4. С. 170-190.

13. Ченцов А.Г. К вопросу о маршрутизации комплексов работ // Вестник Удмуртского университета. Математика. Механика. Компьютерные науки. 2013. Вып. 1. С. 59-82. https://doi.org/10.20537/vm130107

14. Ченцов А.Г., Ченцов П.А. Маршрутизация в условиях ограничений: задача о посещении мегаполисов // Автоматика и телемеханика. 2016. № 11. С. 96-117.

15. Lawler E.L. Efficient implementation of dynamic programming algorithms for sequencing problems / CWI. Technical Reports. Stichting Mathematish Centrum. Mathematische Besliskunde. 1979. BW 106/79 P. 1-16.

16. Ченцов А.Г., Ченцов П.А. Динамическое программирование и эвристические методы в задачах маршрутизации // Известия ЮФУ. Технические науки. 2017. № 9. С. 169-181.

https://doi.org/10.23683/2311-3103-2017-9-169-181

Поступила в редакцию 30.07.2019

Ченцов Александр Георгиевич, д. ф.-м. н., член-корреспондент РАН, главный научный сотрудник, отдел управляемых систем, Институт математики и механики им. Н. Н. Красовского УрО РАН, 620219, Россия, г. Екатеринбург, ул. С. Ковалевской, 16;

профессор, Институт радиоэлектроники и информационных технологий, Уральский федеральный университет, 620002, Россия, г. Екатеринбург, ул. Мира, 19.

E-mail: chentsov@imm.uran.ru

Ченцов Павел Александрович, к. ф.-м. н., старший научный сотрудник, отдел вычислительных сетей, Институт математики и механики им. Н.Н. Красовского УрО РАН, 620219, Россия, г. Екатеринбург, ул. С. Ковалевской, 16;

старший научный сотрудник, Механико-машиностроительный институт, Уральский федеральный университет, 620002, Россия, г. Екатеринбург, ул. Мира, 19.

E-mail: chentsov.p@mail.ru

Цитирование: А.Г. Ченцов, П.А. Ченцов. Маршрутная задача с оптимизацией стартовой точки: динамическое программирование // Известия Института математики и информатики Удмуртского государственного университета. 2019. Т. 54. С. 102-121. 